\title{
AVAILABILITY AND QUALITY OF GROUND WATER IN THE LAKE GEORGE AREA, SOUTHEASTERN PARK COUNTY, COLORADO
}

U.S. GEOLOGICAL SURVEY

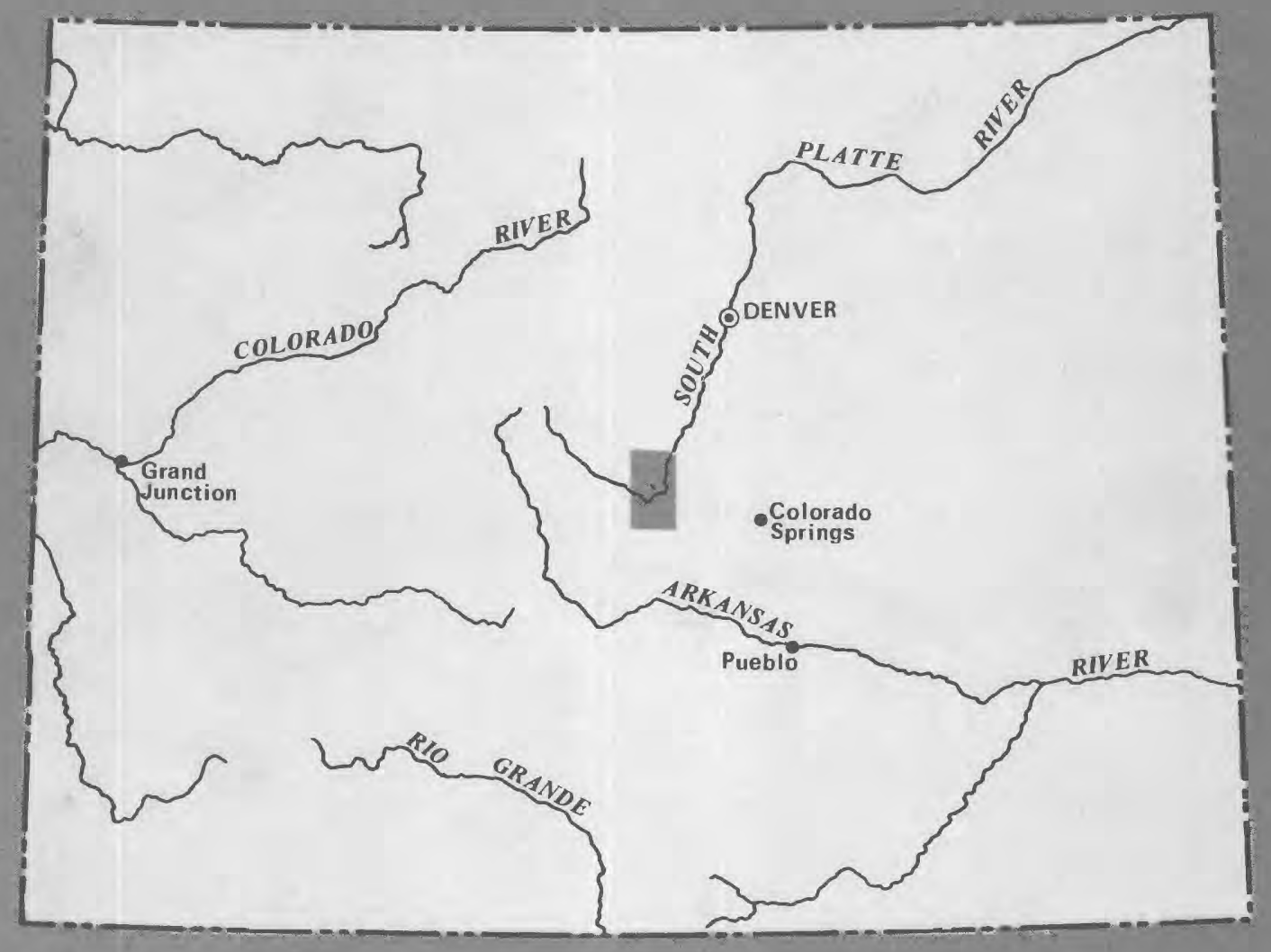

Water Resources Investigations 78-50

Prepared in cooperation with the Park County Board of County Commissioners 


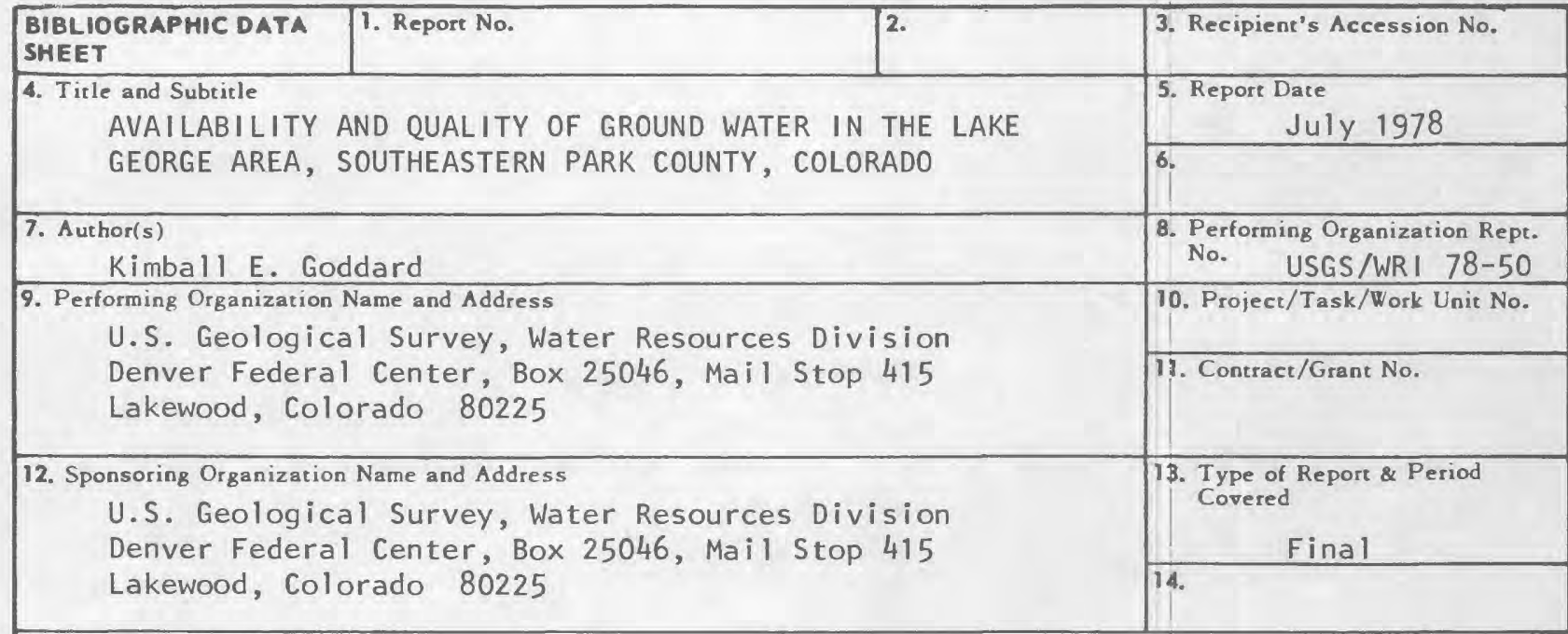

15. Supplementary Nores

Prepared in cooperation with the Park County Board of County Commissioners

16. Abstracts

Water for domestic use in the Lake George area is produced from four aquifers. Two of the aquifers, fractured-crystalline and volcanic rocks, have a water table ranging from 10 to 100 feet below land surface and well yields range from 0.08 to 6 gallons per minute. The consolidated sedimentary-rock and unconsolidated-alluvial aquifers have a water table ranging from near land surface to 60 feet below land surface and well yields range from 2 to 50 gallons per minute.

The aquifers generally contain calcium bicarbonate water with concentrations of dissolved solids ranging from 101 to 636 milligrams per 1 iter. In some areas, concentrations of iron as much as 18,000 micrograms per liter and concentrations of fluoride as much as 5.6 milligrams per liter affect suitability for domestic use. Chemical degradation of ground water has occurred in 18 of the 35 wells and in the 1 spring that were sampled. Bacterial contamination was found in water from 5 ix wells.

17. Key Words and Document Analysis. 17a. Descriptors

Bacteria, Colorado, Domestic waste, Geochemistry, Hydrogeology, Nitrates

17b. Identifiers/Open-Ended Terms

Lake George; Park County, Colorado; South Platte River

17c. COSATI Field/Group

\begin{tabular}{|c|c|c|}
\hline $\begin{array}{l}\text { 18. Availability Statement } \\
\text { No restriction on distribution }\end{array}$ & $\begin{array}{l}\text { 19. Security Class (This } \\
\text { Report) } \\
\text { UNCLASSIFIED }\end{array}$ & $\begin{array}{l}\text { 21. No. of Pages } \\
33\end{array}$ \\
\hline & $\begin{array}{l}\text { 20. Security Class (This } \\
\text { Page } \\
\text { UNCLASSIFIED }\end{array}$ & 22. Price \\
\hline
\end{tabular}


AVAILABILITY AND QUALITY OF GROUND WATER IN THE LAKE GEORGE AREA, SOUTHEASTERN PARK COUNTY, COLORADO

By Kimball E. Goddard

U.S. GEOLOGICAL SURVEY

Water-Resources Investigations 78-50

Prepared in cooperation with the

Park County Board of County Commissioners 


\section{UNITED STATES DEPARTMENT OF THE INTERIOR}

CECIL D. ANDRUS, Secretary

GEOLOGICAL SURVEY

H. William Menard, Director

For additional information write to:

District Chief

U.S. Geological Survey

Box 25046, Mail Stop 415

Denver Federal Center

Lakewood, Colorado 80225 


\section{CONTENTS}

Page
IV

Metric conversions. . . . . . . . . . . . . . . . . . . . . IV

Abstract. . . . . . . . . . . . . . . . . . . . . . . . 1

Introduction. . . . . . . . . . . . . . . . . . . . . . 2

Purpose. . . . . . . . . . . . . . . . . . . 2

Approach ............................. . 2

Acknowledgments. . . . . . . . . . . . . . . . . 4

Ground-water hydrology. . . . . . . . . . . . . . . . . . . . 4

Crystalline-rock aquifer................... . . . 4

Volcanic-rock aquifer. . . . . . . . . . . . . . . . . 6

Consolidated sedimentary-rock aquifer. . . . . . . . . . . . . . 7

Unconsolidated alluvial aquifers................ . 8

Chemical quality of ground water. . . . . . . . . . . . . . . . . . 9

Crystalline-rock aquifer................... . 9

Volcanic-rock aquifer. . . . . . . . . . . . . . . . . 20

Consolidated sedimentary-rock aquifer. . . . . . . . . . . . . . . . 20

Unconsolidated alluvial aquifers . . . . . . . . . . . . . . 21

Effects of domestic waste disposal on ground-water quality . . . . . 21

Summary . . . . . . . . . . . . . . . . . . . . . . . 26

Selected references . . . . . . . . . . . . . . . . . . 27

\section{ILLUSTRATIONS}

Figure 1. Index map showing location of study area . . . . . . . . . . 3

2. Map showing distribution of aquifers and location of surface-water and ground-water sampling sites. . . . . . 5

3. Map and diagrams showing water types and their sources . . . 17

4-6. Maps showing concentrations of:

4. Dissolved iron ............... 18

5. Dissolved fluoride . . . . . . . . . . . . 19

6. Dissolved nitrite plus nitrate as nitrogen ...... 24

TABLES

Table 1. Chemical and bacterial analyses of water from wells and a spring . . . . . . . . . . . . . . . 10

2. Chemical and bacterial analyses of water from selected streams. . . . . . . . . . . . . . . . 


\section{METRIC CONVERSIONS}

U.S. customary units in this report may be expressed as metric units by use of the following conversion factors:

To convert U.S. customary unit

Muztiply by

To obtain metric unit

foot

0.3048

meter

mile

1.6093

ki lometer

gallon per minute

.06309

liter per second

cubic foot per second $\left(\mathrm{ft}^{3} / \mathrm{s}\right)$

.02832

cubic meter per second 
AVAILABILITY AND QUALITY OF GROUND WATER IN THE LAKE GEORGE AREA, SOUTHEASTERN PARK COUNTY, COLORADO

By Kimball E. Goddard

\section{ABSTRACT}

Recognizing that the increasing population of the Lake George area could deplete and degrade the ground water due to increased numbers of wells and septic systems, local officials and the Park County Board of County Commissioners requested the U.S. Geological Survey to conduct a study to determine the hydrologic characteristics of the major aquifers and the chemical quality of the ground water. Aquifers in the Lake George area are found in fractured crystalline and volcanic rocks, in consolidated sedimentary rocks, and in unconsolidated alluvial deposits. The crystalline- and volcanic-rock aquifers underlie most of the study area and are similar in their geohydrologic characteristics. Depths to water range from 10 to 100 feet, and well yields range from 0.08 to 15 gallons per minute. The consolidated sedimentary-rock aquifer underlies a small area near the town of Lake George. Depths to water range from 20 to 60 feet and well yields range from 2 to 18 gallons per minute. The unconsolidated alluvial aquifers principally underlie the valley northwest of Elevenmile Canyon Reservoir and parts of the valleys of the South Platte River and Tarryall Creek. Depths to water range from a few feet to 50 feet but generally range from 10 to 20 feet. Well yields range from 2 to 50 gallons per minute.

The crystalline- and volcanic-rock aquifers yield a calcium bicarbonate water containing dissolved-solids concentrations ranging from 101 to 316 milligrams per liter. Some areas of the crystalline-rock aquifer yield water with concentrations of dissolved iron as much as 18,000 micrograms per liter and with concentrations of dissolved fluoride as much as $5.6 \mathrm{milligrams}$ per liter. The consolidated sedimentary-rock aquifer yields calcium bicarbonate and calcium sulfate water with dissolved-solids concentrations ranging from 203 to 636 milligrams per liter. Dissolved iron concentrations range from 1,300 to 5,100 micrograms per liter. The unconsolidated alluvial aquifers yield calcium bicarbonate and sodium chloride water with dissolved-solids concentrations ranging from 213 to $455 \mathrm{milligrams}$ per liter.

Concentrations of dissolved nitrite plus nitrate as nitrogen equal or greater than $0.25 \mathrm{milligram}$ per liter--the value determined to be indicative 
of chemical degradation--were found in water from 18 of the 35 wells and from the 1 spring that were sampled. However, water from only one well was found to contain a concentration of dissolved nitrite plus nitrate as nitrogen in excess of the Colorado Department of Health's recommended limit for domestic use. Fecal streptococci were found in samples from six wells but fecal coliforms were not detected in water from any of the wells or from the spring.

Degradation of ground water from domestic waste disposal occurs throughout the area but is not a serious problem at the present time (1976). However, geohydrologic conditions are such that additional and possible serious degradation of ground water could occur with increasing use of on-lot domestic waste-disposal systems.

\section{INTRODUCTION}

Located on the South Platte River about 30 miles west of Colorado springs, Colo. ( $\mathrm{fig} .1$ ), Lake George is surrounded by the rolling and mountainous, tree-covered terrain characteristic of the Front Range in Colorado. The area's attractive setting, plus the proximity of major recreational sites, such as Elevenmile Canyon Reservoir and Elevenmile Canyon, has resulted in an increasing number of people visiting and building summer homes in the town of Lake George and the surrounding mountains. Ten new subdivisions have been platted that will use ground water for the water supply. Individual property owners will dispose of domestic wastes in on-lot sewage-treatment facilities. On-lot sewage-treatment facilities can cause degradation of ground and surface water if they are not located in a geohydrologic environment that can assimilate the wastes.

\section{Purpose}

Recognizing that a serious ground-water pollution problem could develop in the Lake George area, local officials and the Park County Board of County Commissioners requested the U.S. Geological Survey to conduct a ground-water study of the area. The principal objectives of the study were to determine: The general hydrologic characteristics of the major aquifers, the chemical quality of the ground water, and whether or not on-lot domestic waste-disposal practices are degrading ground-water quality.

\section{Approach}

A study of the general hydrology of Park and Teller Counties by Klein, Goddard, and Livingston (1978) provided the basic hydrologic data used in this report. A study of the mountainous part of Jefferson County (Hofstra and Hall, 1975) provided knowledge of the basic relationships involved in studies of crystalline-rock terrains. To supplement these data, additional data were collected during the summer and fall of 1975. 

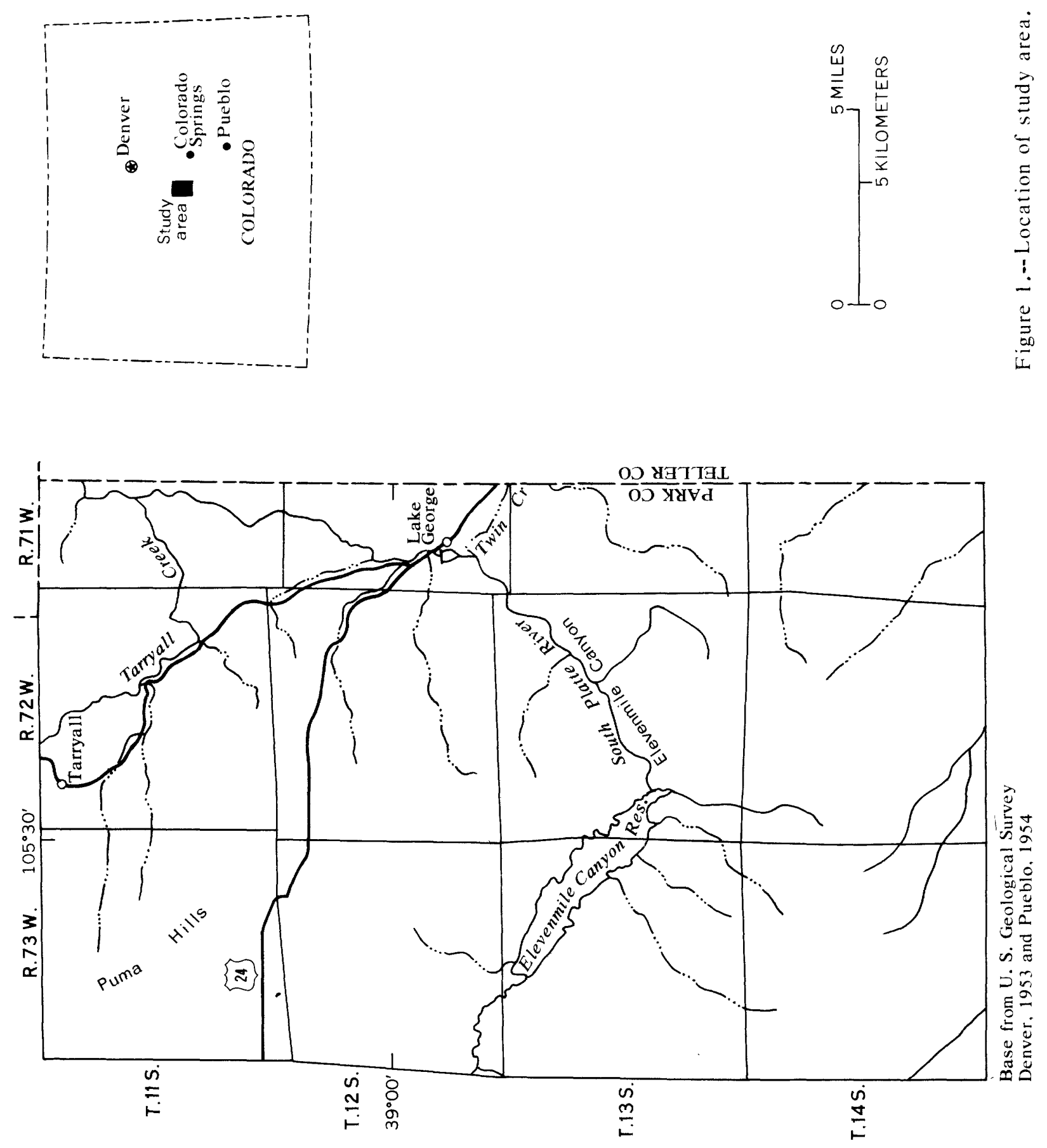
Geohydrologic data were obtained for 35 wells and 1 spring. These data, in conjunction with records of wells provided by the Colorado State Engineer's office, were used to determine average ground-water levels, well depths, and well yields. Water samples from the 35 wells and 1 spring were analyzed to determine the quality of the ground water. Four water samples from three streams were analyzed to determine the quality of surface water. Because some areas within the study boundaries are presently undeveloped and wells do not exist, there are not sufficient data to adequately evaluate local ground-water characteristics.

\section{Acknowledgments}

The author wishes to thank the many residents of the project area who permitted access to and sampling from their wells. The help of the Park County Land Use Administrator who provided information on subdivisions and maps of the study area is gratefully acknowledged.

\section{GROUND-WATER HYDROLOGY}

Based on geohydrologic properties, the rock units found in the study area can be divided into four aquifers. Crystalline rocks, which include gneiss, schist, and granite, underlie the entire study area. Where these rocks are exposed at the surface, principally in the northeastern one-half of the study area, they comprise the crystalline-rock aquifer. Volcanic rocks, which include rhyolitic, andesitic, and basaltic flows, flow breccias, and tuffs, overlie the crystalline rocks principally in the southwestern part of the study area and comprise the volcanic-rock aquifer. Consolidated sedimentary rocks, which consist primarily of andesitic ash particles cemented together, occur in a narrow northwest-trending band near the town of Lake George and comprise the consolidated sedimentary-rock aquifer. Unconsolidated deposits, which include clay, sand, and fine to coarse gravel, occur principally in the valley northwest of Elevenmile Canyon Reservoir and along parts of the valleys of the South Platte River and Tarryall Creek and comprise the unconsolidated alluvial aquifers. The general distribution of the aquifers in the study area is shown on figure 2 .

\section{Crystalline-Rock Aquifer}

Crystalline rocks underlie the entire Lake George study area. Two general divisions of crystalline rocks are present--a complex of coarsely crystalline metamorphic rocks and a series of medium- to coarse-grained granitic rocks of plutonic origin, which were intruded into the metamorphic rocks.

The structures present in the crystalline rocks that control the occurrence and movement of ground water are faults and joints which are collectively referred to as fractures. The joints, the most common of the 


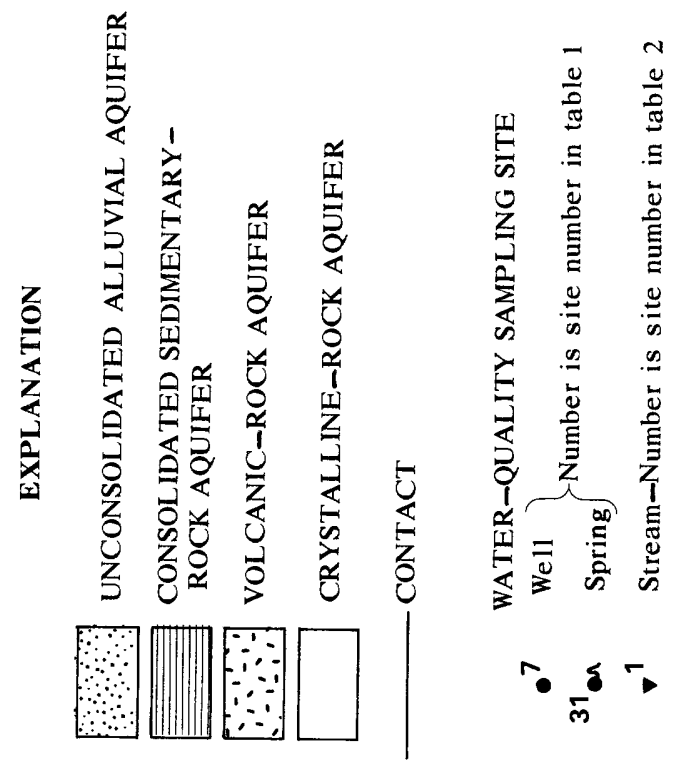

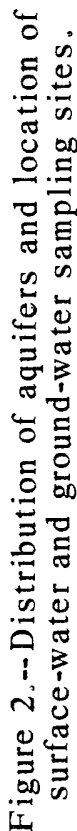

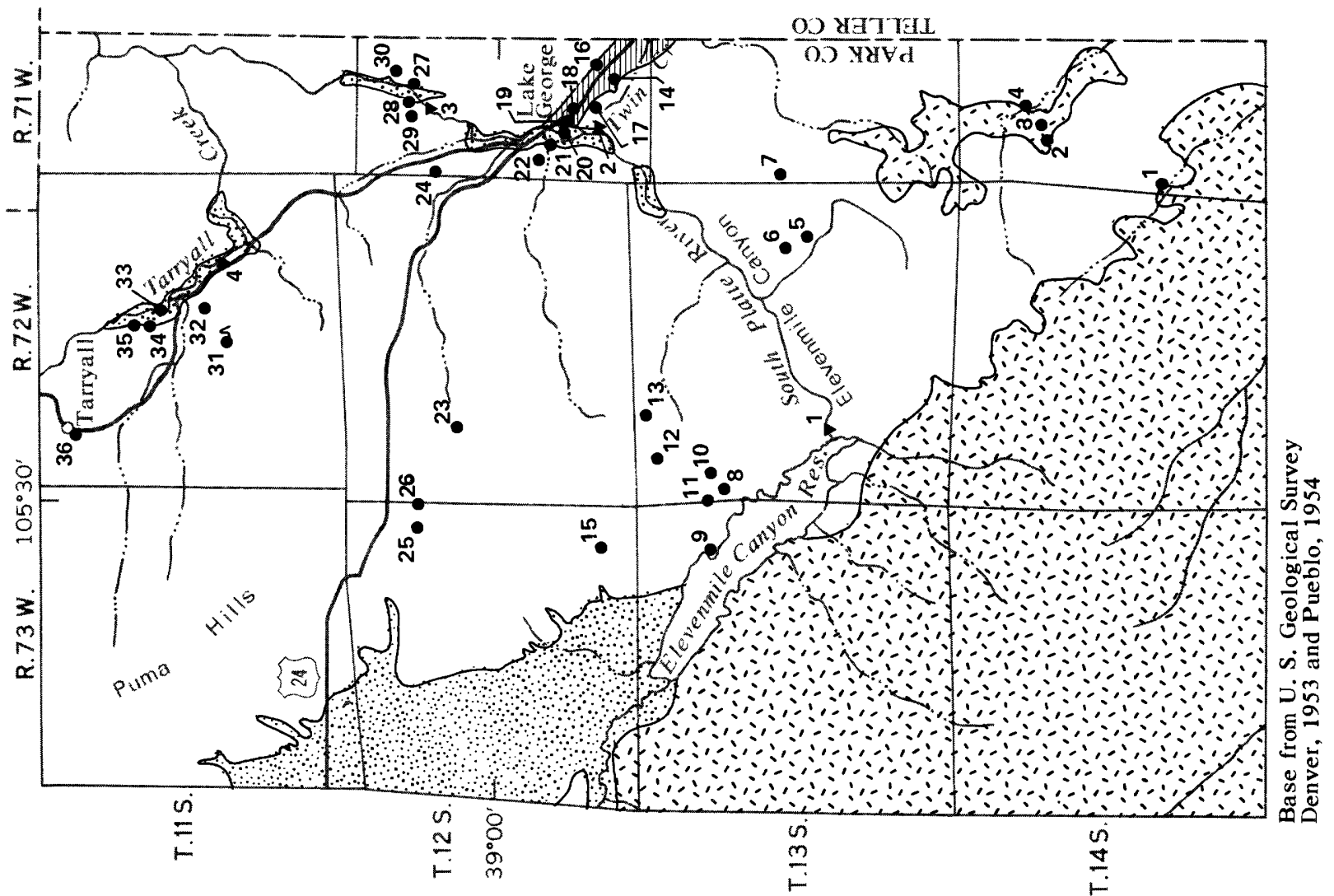


fractures present, are affected by weathering and, therefore, are more common and larger near the land surface. According to Hofstra and Hall (1975), the general fracture pattern found in crystalline rocks of the Front Range in Colorado can be divided into three zones. The upper zone extends from the land surface to a depth of about 40 feet and is characterized by abundant open fractures. The middle zone extends from a depth of about 40 feet to a depth of about 200 feet and is characterized by fewer and narrower fractures than occur in the upper zone. The lower zone occurs at depths greater than 200 feet, where water-bearing fractures are few or nonexistent. The fractures are generally high-angle features--70 to 90 degrees from horizontal--with width and degree of interconnection extremely variable, both horizontally and vertically. The fractures form a poorly connected network that contains and transmits small amounts of ground water.

The fractured crystalline-rock aquifer is characterized by relatively low storage capacity and low hydraulic conductivity. This results in rather large water-level fluctuations when water in the aquifer is recharged by precipitation or depleted by well withdrawal. Generally, the depth to water below land surface is closely related to topography. Water levels are deepest in wells drilled on the flanks or tops of hills, and shallowest in wells drilled on flat areas or in valley bottoms, especially near streams. In most areas where the crystalline rock occurs at the surface, ground water is found at depths of from 10 to 100 feet.

Well depth follows the same general relationship as depth to water; wells are deepest on the flanks and tops of hills and shallowest in valley bottoms. Wells tapping the crystalline-rock aquifer range in depth from 50 feet to as much as 300 feet with the average well extending 150 feet below land surface.

The yields of wells drilled into the crystalline-rock aquifer are determined by the number and size of intersected water-bearing fractures. In general, due to the limited number of fractures intersected by a well, yields range from 0.08 to 15 gallons per minute. Based on records of 97 wells, a well in the Lake George study area can be expected to yield from 1 to 3 gallons per minute from the crystalline-rock aquifer.

There also exists a correlation between well depth and well yield. Due to the limited number of water-bearing fractures located more than 200 feet below land surface, wells which need to be drilled deeper tend to have yields ranging from 0.08 to 2.5 gallons per minute. A few unsuccessful wells also have been drilled in the study area. An adequate water supply was not developed from these wells that ranged in depth from 90 to 225 feet.

\section{Volcanic-Rock Aquifer}

The southwestern part of the study area is covered by an extensive deposit of volcanic rocks. These deposits of fine-grained crystalline rocks consist of a series of basalt flows, flow breccias, and ash falls erupted from 
a center several miles southwest of the study area. This unit is several thousand feet thick in some areas.

The features present in the volcanic rocks that control the occurrence and movement of ground water are interconnected gas vesicles, shrinkage structures, open space between breccia fragments, and fractures. The porosity, hydraulic conductivity, and transmissivity of the volcanic-rock aquifer is extremely variable due to localization of specific types of voids. The water is located in and moves through open voids. However, unlike the crystalline rocks, these voids are not concentrated near the land surface but are spread unevenly thoughout the aquifer.

Due to lack of development in the southwestern part of the study area, few wells have been drilled into the volcanic rocks. The information presented below is based on well logs from six wells; it represents local conditions only and may not be applicable to the entire area underlain by volcanic rocks. In general, the volcanic-rock aquifer in the Lake George area is hydrologically similar to the crystalline-rock aquifer and is characterized by deep wells with relatively small yields.

Water levels and well depths are strongly influenced by topography, being shallow in the valleys and deeper on hillsides and hilltops. Water levels range from 20 to 100 feet below land surface. The wells drilled into the volcanic rocks range in depth from 35 to 210 feet and the median depth is 105 feet.

In the Lake George study area, yields from wells tapping the volcanicrock aquifer generally range from 0.5 to 5 gallons per minute. The typical well yields 0.5 to 2 gallons per minute.

\section{Consolidated Sedimentary-Rock Aquifer}

Consolidated sedimentary rocks underlie the town of Lake George and the valley to the east of the town. These deposits formed synchronously with eruption of the volcanic rocks. Ash fell into a large fresh-water lake, which then occupied the valley, and was deposited on the lake floor. The lake beds consist almost entirely of andesitic volcanic ash. The thickness is quite variable with a maximum of about 300 feet. However, the deposits are generally less than 200 feet thick.

The lake deposits have the same hydrologic characteristics as siltstone. Water is located in and moves through voids between the individual ash particles. The volume of void space, or porosity, in rock comprised of siltsize particles ranges from 40 to 50 percent (Todd, 1959). The voids are so small, however, that surface-tension forces hold a large percentage of ground water in place against gravity. Even so, the consolidated sedimentary rocks are characterized by greater storage capacity and hydraulic conductivity than the crystalline and volcanic rocks. 
This unit would not be considered an important aquifer because of its limited areal extent, except that it underlies the town of Lake George. Even though the area is the most densely populated within the study boundaries, there are few data available, because many of the wells were drilled before adequate records were kept. Also, about one-half of the wells drilled into the lake beds penetrate the unit and extend into the underlying crystalline rocks. Therefore, knowledge of the hydrologic characteristics of the consolidated sedimentary-rock aquifer is based on limited data and is generalized.

The water table ranges in depth from 20 to 60 feet, with the typical well intersecting the water table 40 feet below the land surface. Wells completed in the lake beds range in depth from 33 to 165 feet. Wells as deep as 300 feet penetrate the unit. Well yields range from 2 to 18 gallons per minute and average about 10 gallons per minute. Wells drilled into the lake beds generally produce water supplies adequate for domestic use.

\section{Unconsolidated Alluvial Aquifers}

The area northwest of Elevenmile Canyon Reservoir is covered by a mantle of alluvium (fig. 2). These deposits were formed from debris eroded from the Puma Hills and consist of tan to light-brown sandy soil with angular to subrounded pebbles and cobbles. The thickness of the alluvium is as much as 100 feet just northwest of Elevenmile Canyon Reservoir (R. A. Wobus, oral commun., 1976).

Limited deposits of alluvial gravel occur along all major and most minor drainages throughout the study area. Due to their small size and discontinuous nature, most of these deposits are not shown on the aquifer map (fig. 2). The alluvium tends to be coarse sand and gravel, with large boulders, cobbles, and pebbles common. The thickness is variable, ranging from only a few feet to more than 80 feet.

According to Todd (1959), a mixture of sand and gravel has between 20 and 35 percent void space. These voids are located between grains of sand and gravel and their ability to store and transmit ground water is dependent on the size and sorting of the grains. Alluvial aquifers are characterized by their ability to store and transmit relatively large amounts of ground water.

The extensive mantle of alluvium that covers large areas northwest of Elevenmile Canyon Reservoir is undeveloped. Only a few domestic and stock wells penetrate the alluvium and few data are available. Hence, the following discussion will center on the less extensive but much more developed alluvial gravels found along the South Platte River, Tarryall Creek, and other major and minor drainages in the study area.

The location of alluvial material in valley bottoms and along stream courses allows recharge from precipitation, surface water, and ground water 
draining from the surrounding higher terrain. Water levels are stable and shallow because of the recharge, high storage capacities, and high hydraulic conductivities of the alluvial aquifers. Water levels range from only a few feet to a maximum of 50 feet below land surface. The water table in the alluvial aquifers is generally between 10 and 20 feet below land surface.

Because of the factors discussed above, wells drilled in alluvial aquifers need only extend a short distance below the water table to produce an adequate supply of water for domestic use. Wells tapping alluvial aquifers generally range in depth from 10 to 80 feet. The typical alluvial well is between 25 and 35 feet deep.

The yields of wells drilled into unconsolidated alluvial aquifers depend on the saturated thickness penetrated, the distance from any recharging ground or surface water, and to a much lesser extent the diameter of the well. In general, yields are more than adequate for domestic supplies, ranging from 2 to 50 gallons per minute. A typical well will yield from 5 to 15 gallons per minute.

\section{CHEMICAL QUALITY OF GROUND WATER}

The chemical quality of ground water found in the Lake George study area is the result of many factors, including the chemical quality of the source water, composition and solubility of the aquifer materials, to some extent the length of contact time with the aquifer, and the effects of man. The chemical characteristics, as discussed in the following sections, take into account all these factors except the effects of man resulting from disposal of domestic wastes. The final section describes the particular water-quality problems found in the study area resulting from waste-water disposal by septic systems.

Chemical-quality data were obtained from all major aquifers in the study area. Chemical-quality data were also collected at selected surface-water sites. Points at which water samples were collected are shown on figure 2 and the chemical analyses are included in tables 1 and 2 .

\section{Crystalline-Rock Aquifer}

The chemical character of water from the crystalline-rock aquifer is the result of the quality of the recharge water--mainly precipitation--plus small amounts of constituents dissolved from overlying and aquifer materials. The rocks comprising the crystalline-rock aquifer, being resistant to chemical weathering, only slightly affect the quality of water. The relative insolubility of the aquifer material is characterized by dissolved-solids concentrations that ranged from 101 to $316 \mathrm{mg} / \mathrm{L}$ (milligrams per liter) in water that has not been affected by waste disposal. 
Table 1.--Chemical and bacterial analyses of water from wells and a spring [MG/L=milligrams per liter; $M L=m i l l i l i t e r s ; U G / L=m i c r o g r a m s$ per $1 i$ ter ]

\begin{tabular}{|c|c|c|c|c|c|c|}
\hline $\begin{array}{l}\text { SITE } \\
\text { NUM- } \\
\text { BER }\end{array}$ & STATION & $\begin{array}{l}\text { DATE } \\
\text { OF } \\
\text { SAMPLE } \\
(Y-M-D)\end{array}$ & AQUIFER & $\begin{array}{l}\text { DIS- } \\
\text { SOLVED } \\
\text { SILICA } \\
(S I O Z) \\
(M G / L)\end{array}$ & $\begin{array}{l}\text { OIS- } \\
\text { SOLVED } \\
\text { IRON } \\
\text { (FE) } \\
\text { (UG/L) } \\
\text { I[300] }\end{array}$ & $\begin{array}{l}\text { DIS- } \\
\text { SOLVED } \\
\text { MAN- } \\
\text { GANESE } \\
\text { (MN) } \\
\text { (UG/L) } \\
{[50]} \\
\end{array}$ \\
\hline $\begin{array}{l}1 \\
2 \\
3 \\
4 \\
5\end{array}$ & $\begin{array}{l}384857105230800 \\
385046105215000 \\
385050105213800 \\
385100105205200 \\
385426105235100\end{array}$ & $\begin{array}{l}75-08-12 \\
75-08-12 \\
75-08-12 \\
75-08-12 \\
75-11-04\end{array}$ & $\begin{array}{l}\text { VOLCANIC ROCK } \\
\text { UNCONSOLIDATED ALLUVIUM } \\
\text { VOLCANIC ROCK } \\
\text { CRYSTALLINE ROCK } \\
\text { CRYSTALLINE ROCK }\end{array}$ & $\begin{array}{l}23 \\
24 \\
16 \\
23 \\
23\end{array}$ & $\begin{array}{l}10 \\
30 \\
30 \\
40 \\
10\end{array}$ & $\begin{array}{r}0 \\
0 \\
0 \\
20 \\
6\end{array}$ \\
\hline $\begin{array}{r}6 \\
7 \\
8 \\
9 \\
10\end{array}$ & $\begin{array}{l}385456105235300 \\
385512105222200 \\
385605105293500 \\
385620105304700 \\
385630105290500\end{array}$ & $\begin{array}{l}75-11-04 \\
75-11-04 \\
75-08-14 \\
75-11-05 \\
75-08-14\end{array}$ & $\begin{array}{l}\text { CRYSTALLINE ROCK } \\
\text { CRYSTALLINE ROCK } \\
\text { CRYSTALLINE ROCK } \\
\text { CRYSTALLINE ROCK } \\
\text { CRYSTALLINE ROCK }\end{array}$ & $\begin{array}{l}28 \\
16 \\
21 \\
13 \\
20\end{array}$ & $\begin{array}{r}20 \\
0 \\
0 \\
0 \\
40\end{array}$ & $\begin{array}{r}10 \\
4 \\
0 \\
10 \\
0\end{array}$ \\
\hline $\begin{array}{l}11 \\
12 \\
13 \\
14 \\
15\end{array}$ & $\begin{array}{l}385633105295200 \\
385730105284000 \\
385737105273600 \\
385804105202200 \\
385813105301500\end{array}$ & $\begin{array}{l}75-08-13 \\
75-08-13 \\
75-08-13 \\
75-11-04 \\
75-08-13\end{array}$ & $\begin{array}{c}\text { CRYSTALLINE ROCK } \\
\text { CRYSTALLINE ROCK } \\
\text { CRYSTALLINE ROCK } \\
\text { CONSOLIDATED SEDIMENTARY ROCK } \\
\text { CRYSTALLINE ROCK }\end{array}$ & $\begin{array}{l}21 \\
18 \\
19 \\
31 \\
24\end{array}$ & $\begin{array}{r}20 \\
\frac{1300}{30} \\
\frac{3100}{30}\end{array}$ & $\begin{array}{r}\frac{340}{260} \\
\frac{330}{0}\end{array}$ \\
\hline $\begin{array}{l}16 \\
17 \\
18 \\
19 \\
20\end{array}$ & $\begin{array}{l}385815105200500 \\
385834105205600 \\
385845105211000 \\
385848105212700 \\
385850105221200\end{array}$ & $\begin{array}{l}75-11-04 \\
75-11-04 \\
75-11-04 \\
75-11-04 \\
75-08-13\end{array}$ & $\begin{array}{c}\text { CRYSTALLINE ROCK } \\
\text { CONSOLIDATED SEDIMENTARY ROCK } \\
\text { CONSOLIDATED SEDIMENTARY ROCK } \\
\text { CRYSTALLINE ROCK } \\
\text { UNCONSOLIDATED ALLUVIUM }\end{array}$ & $\begin{array}{l}37 \\
68 \\
45 \\
55 \\
28\end{array}$ & $\frac{\frac{780}{100}}{1400}$ & $\begin{array}{r}\frac{310}{550} \\
40 \\
30 \\
30\end{array}$ \\
\hline $\begin{array}{l}21 \\
22 \\
23 \\
24 \\
25\end{array}$ & $\begin{array}{l}385902105214000 \\
385914105215600 \\
390038105282000 \\
390117105223700 \\
3901117105302500\end{array}$ & $\begin{array}{l}75-11-06 \\
75-11-04 \\
75-11-05 \\
75-11-05 \\
75-08-13\end{array}$ & $\begin{array}{l}\text { CRYSTALLINE ROCK } \\
\text { CONSOLIDATED SEDIMENTARY ROCK } \\
\text { CRYSTALLINE ROCK } \\
\text { CRYSTALLINE ROCK } \\
\text { CRYSTALLINE ROCK }\end{array}$ & $\begin{array}{l}25 \\
30 \\
26 \\
27 \\
23\end{array}$ & $\begin{array}{r}1300 \\
30 \\
0 \\
40\end{array}$ & $\frac{\frac{160}{100}}{10}$ \\
\hline $\begin{array}{l}26 \\
27 \\
28 \\
29 \\
30\end{array}$ & $\begin{array}{l}390121105294700 \\
390140105204700 \\
390142105205700 \\
390143105210300 \\
390205105203400\end{array}$ & $\begin{array}{l}75-08-14 \\
75-08-15 \\
75-08-15 \\
75-08-15 \\
75-08-15\end{array}$ & $\begin{array}{l}\text { CRYSTALLINE ROCK } \\
\text { CRYSTALLINE ROCK } \\
\text { UNCONSOLIDATED ALLUVIUM } \\
\text { CRYSTALLINE ROCK } \\
\text { CRYSTALLINE ROCK }\end{array}$ & $\begin{array}{l}17 \\
25 \\
13 \\
20 \\
21\end{array}$ & $\begin{array}{r}20 \\
10 \\
0 \\
20 \\
60\end{array}$ & $\begin{array}{r}160 \\
10 \\
0 \\
10 \\
10\end{array}$ \\
\hline $\begin{array}{l}31 \\
32 \\
33 \\
34 \\
35\end{array}$ & $\begin{array}{l}390417105271100 \\
390514105252800 \\
390552105254500 \\
390602105255500 \\
390638105260700\end{array}$ & $\begin{array}{l}75-08-14 \\
75-11-05 \\
75-08-14 \\
75-08-14 \\
75-08-14\end{array}$ & $\begin{array}{l}\text { UNCONSOLIDATED ALLUVIUM } \\
\text { CRYSTALLINE ROCK } \\
\text { CRYSTALLINE ROCK } \\
\text { CRYSTALLINE ROCK } \\
\text { CRYSTALLINE ROCK }\end{array}$ & $\begin{array}{l}20 \\
19 \\
30 \\
30 \\
25\end{array}$ & $\begin{array}{r}0 \\
0 \\
18000 \\
0 \\
10000 \\
\end{array}$ & $\begin{array}{r}0 \\
0 \\
880 \\
60 \\
380 \\
\end{array}$ \\
\hline 36 & 390719105282900 & $75-11-06$ & CRYSTALLINE ROCK & 16 & 0 & 2 \\
\hline
\end{tabular}


Table 1.--Chemical and bacterial analyses of water from wells and a spring--Continued

\begin{tabular}{|c|c|c|c|c|c|c|c|c|}
\hline $\begin{array}{l}\text { SITE } \\
\text { NUMY } \\
\text { BER }\end{array}$ & STATION & $\begin{array}{c}\text { DATE } \\
\text { OF } \\
\text { SAMPLE } \\
(Y-M-D)\end{array}$ & $\begin{array}{l}\text { DIS- } \\
\text { SOLVED } \\
\text { CAL- } \\
\text { CIUM } \\
\text { (CA) } \\
\text { (MG/L) }\end{array}$ & $\begin{array}{l}\text { DIS- } \\
\text { SOLVEO } \\
\text { MAG- } \\
\text { NE- } \\
\text { SIUM } \\
\text { (MG) } \\
\text { (MG/L) } \\
{[125]}\end{array}$ & $\begin{array}{l}\text { DIS- } \\
\text { SOLVED } \\
\text { SODIUM } \\
\text { (NA) } \\
\text { (MG/L) }\end{array}$ & $\begin{array}{l}\text { OIS- } \\
\text { SOLVED } \\
\text { PO- } \\
\text { TAS- } \\
\text { SIUM } \\
\text { (K) } \\
\text { (MG/L) }\end{array}$ & $\begin{array}{l}\text { BICAR - } \\
\text { BONATE } \\
\text { (HCO3) } \\
\text { (MG/L) }\end{array}$ & $\begin{array}{l}\text { CAR- } \\
\text { BONATE } \\
\text { (CO3) } \\
\text { (MG/L) }\end{array}$ \\
\hline $\begin{array}{l}1 \\
2 \\
3 \\
4 \\
5\end{array}$ & $\begin{array}{l}384857105230800 \\
385046105215000 \\
385050105213800 \\
385100105205200 \\
385426105235100\end{array}$ & $\begin{array}{l}75-08-12 \\
75-08-12 \\
75-08-12 \\
75-08-12 \\
75-11-04\end{array}$ & $\begin{array}{l}52 \\
51 \\
2.5 \\
37 \\
51\end{array}$ & $\begin{array}{l}10 \\
11 \\
. .3 \\
7.4 \\
9.6\end{array}$ & $\begin{array}{l}13 \\
14 \\
50 \\
13 \\
15\end{array}$ & $\begin{array}{r}1.1 \\
1.1 \\
.1 \\
: 8 \\
1.2\end{array}$ & $\begin{array}{l}195 \\
190 \\
102 \\
170 \\
204\end{array}$ & $\begin{array}{r}0 \\
0 \\
13 \\
0 \\
0\end{array}$ \\
\hline $\begin{array}{r}6 \\
7 \\
8 \\
9 \\
10\end{array}$ & $\begin{array}{l}385456105235300 \\
385512105222200 \\
385605105293500 \\
385620105304700 \\
385630105290500\end{array}$ & $\begin{array}{l}75-11-04 \\
75-11-04 \\
75-08-14 \\
75-11-05 \\
75-08-14\end{array}$ & $\begin{array}{l}38 \\
52 \\
88 \\
60 \\
54\end{array}$ & $\begin{array}{l}6.1 \\
10 \\
15 \\
11 \\
9.0\end{array}$ & $\begin{array}{l}12 \\
13 \\
26 \\
11 \\
14\end{array}$ & $\begin{array}{l}.8 \\
1.4 \\
2.0 \\
4.2 \\
1.4\end{array}$ & $\begin{array}{l}133 \\
218 \\
299 \\
160 \\
192\end{array}$ & $\begin{array}{c}0 \\
0 \\
-0 \\
0\end{array}$ \\
\hline $\begin{array}{l}11 \\
12 \\
13 \\
14 \\
15\end{array}$ & $\begin{array}{l}385633105295200 \\
385730105284000 \\
385737105273600 \\
385804105202200 \\
385813105301500\end{array}$ & $\begin{array}{l}75-08-13 \\
75-08-13 \\
75-08-13 \\
75-11-04 \\
75-08-13\end{array}$ & $\begin{array}{l}36 \\
24 \\
43 \\
47 \\
44\end{array}$ & $\begin{array}{r}6.0 \\
3.5 \\
6.3 \\
11 \\
8.8\end{array}$ & $\begin{array}{l}10 \\
6.2 \\
9.6 \\
6.7 \\
16\end{array}$ & $\begin{array}{l}1.1 \\
7.8 \\
1.6 \\
2.3 \\
2.2\end{array}$ & $\begin{array}{r}146 \\
87 \\
156 \\
166 \\
96\end{array}$ & $\begin{array}{l}-- \\
-- \\
--\end{array}$ \\
\hline $\begin{array}{l}16 \\
17 \\
18 \\
19 \\
20\end{array}$ & $\begin{array}{l}385815105200500 \\
385834105205600 \\
385845105211000 \\
385848105212700 \\
385850105221200\end{array}$ & $\begin{array}{l}75-11-04 \\
75-11-04 \\
75-11-04 \\
75-11-04 \\
75-08-13\end{array}$ & $\begin{array}{r}40 \\
110 \\
32 \\
80 \\
56\end{array}$ & $\begin{array}{l}8.5 \\
16 \\
5.3 \\
11 \\
10\end{array}$ & $\begin{array}{l}8.0 \\
27 \\
20 \\
17 \\
13\end{array}$ & $\begin{array}{l}2.9 \\
9.3 \\
4.3 \\
7.6 \\
3.1\end{array}$ & $\begin{array}{l}165 \\
6 \\
153 \\
185 \\
211\end{array}$ & $\begin{array}{r}0 \\
0 \\
0 \\
0 \\
-\cdots\end{array}$ \\
\hline $\begin{array}{l}21 \\
22 \\
23 \\
24 \\
25\end{array}$ & $\begin{array}{l}385902105214000 \\
385914105215600 \\
390038105282000 \\
390117105223700 \\
390117105302500\end{array}$ & $\begin{array}{l}75-11-06 \\
75-11-04 \\
75-11-05 \\
75-11-05 \\
75-08-13\end{array}$ & $\begin{array}{l}35 \\
92 \\
93 \\
70 \\
23\end{array}$ & $\begin{array}{l}4.6 \\
16 \\
28 \\
13 \\
5.5\end{array}$ & $\begin{array}{l}8.4 \\
42 \\
53 \\
19 \\
12\end{array}$ & $\begin{array}{l}2.5 \\
4.6 \\
3.8 \\
3.7 \\
1.6\end{array}$ & $\begin{array}{r}93 \\
266 \\
482 \\
263 \\
102\end{array}$ & $\begin{array}{r}0 \\
0 \\
0 \\
0 \\
--\end{array}$ \\
\hline $\begin{array}{l}26 \\
27 \\
28 \\
29 \\
30\end{array}$ & $\begin{array}{l}390121105294700 \\
3901140105204700 \\
3901142105205700 \\
390143105210300 \\
390205105203400\end{array}$ & $\begin{array}{l}75-08-14 \\
75-08-15 \\
75-08-15 \\
75-08-15 \\
75-08-15\end{array}$ & $\begin{array}{l}30 \\
25 \\
66 \\
29 \\
21\end{array}$ & $\begin{array}{l}6.9 \\
2.2 \\
20 \\
4.5 \\
1.7\end{array}$ & $\begin{array}{l}17 \\
85 \\
67 \\
6.5 \\
5.9\end{array}$ & $\begin{array}{l}1.7 \\
2.8 \\
2.6 \\
3.4 \\
2.5\end{array}$ & $\begin{array}{l}146 \\
109 \\
240 \\
73 \\
65\end{array}$ & $\begin{array}{l}=- \\
\ddot{-} \\
--\end{array}$ \\
\hline $\begin{array}{l}31 \\
32 \\
33 \\
34 \\
35\end{array}$ & $\begin{array}{l}390417105271100 \\
390514105252800 \\
390552105254500 \\
390602105255500 \\
390638105260700\end{array}$ & $\begin{array}{l}75-08-14 \\
75-11-05 \\
75-08-14 \\
75-08-14 \\
75-08-14\end{array}$ & $\begin{array}{l}41 \\
39 \\
58 \\
31 \\
42\end{array}$ & $\begin{array}{r}9.7 \\
5.5 \\
11 \\
3.1 \\
7.7\end{array}$ & $\begin{array}{l}18 \\
13 \\
30 \\
11 \\
20\end{array}$ & $\begin{array}{l}2.9 \\
3.2 \\
1.2 \\
.8 \\
1.5\end{array}$ & $\begin{array}{r}173 \\
78 \\
244 \\
77 \\
134\end{array}$ & $\begin{array}{r}0 \\
0 \\
-- \\
--\end{array}$ \\
\hline 36 & 390719105282900 & $75-11-06$ & 57 & 11 & 13 & 3.5 & 188 & 0 \\
\hline
\end{tabular}


Table 1.--Chemical and bacterial analyses of water from wells and a spring--Continued

\begin{tabular}{|c|c|c|c|c|c|c|c|}
\hline $\begin{array}{l}\text { SITE } \\
\text { NUMY } \\
\text { BER }\end{array}$ & STATION & $\begin{array}{l}\text { DATE } \\
\text { OF } \\
\text { SAMPLE } \\
(Y-M-D)\end{array}$ & $\begin{array}{l}\text { ALKA- } \\
\text { LINITY } \\
\text { AS } \\
\text { CACO3 } \\
\text { (MG/L) }\end{array}$ & $\begin{array}{c}\text { DIS- } \\
\text { SOLVED } \\
\text { SULFATE } \\
\text { (SO4) } \\
\text { (MG/L) } \\
{[250]}\end{array}$ & $\begin{array}{l}\text { OIS- } \\
\text { SOLVED } \\
\text { CHLO- } \\
\text { RIDE } \\
\text { (CL) } \\
\text { (MG/L) } \\
\text { [250] }\end{array}$ & $\begin{array}{c}\text { DIS- } \\
\text { SOLVED } \\
\text { FLUO- } \\
\text { RIDE } \\
\text { (F) } \\
(M G / L) \\
{[1.3]} \\
\end{array}$ & $\begin{array}{c}\text { DIS- } \\
\text { SOLVED } \\
\text { NITRITE } \\
\text { PLUS } \\
\text { NITRATE } \\
\text { (N) } \\
\text { (MG/L) } \\
{[10.0]}\end{array}$ \\
\hline $\begin{array}{l}1 \\
2 \\
3 \\
4 \\
5\end{array}$ & $\begin{array}{l}384857105230800 \\
385046105215000 \\
385050105213800 \\
385100105205200 \\
385426105235100\end{array}$ & $\begin{array}{l}75-08-12 \\
75-08-12 \\
75-08-12 \\
75-08-12 \\
75-11-04\end{array}$ & $\begin{array}{l}160 \\
156 \\
105 \\
139 \\
167\end{array}$ & $\begin{array}{l}30 \\
34 \\
8.5 \\
14 \\
12\end{array}$ & $\begin{array}{l}7.6 \\
4.9 \\
2.6 \\
2.8 \\
6.9\end{array}$ & $\begin{array}{l}\frac{1.4}{1.1} \\
.7 \\
1.8 \\
1.3\end{array}$ & $\begin{array}{l}1.0 \\
.26 \\
.02 \\
.08 \\
1.1\end{array}$ \\
\hline $\begin{array}{r}6 \\
7 \\
8 \\
9 \\
10\end{array}$ & $\begin{array}{l}385456105235300 \\
385512105222200 \\
385605105293500 \\
385620105304700 \\
385630105290500\end{array}$ & $\begin{array}{l}75-11-04 \\
75-11-04 \\
75-08-14 \\
75-11-05 \\
75-08-14\end{array}$ & $\begin{array}{l}109 \\
179 \\
245 \\
131 \\
157\end{array}$ & $\begin{array}{l}25 \\
9.7 \\
71 \\
78 \\
34\end{array}$ & $\begin{array}{l}3.3 \\
3.8 \\
11 \\
9.8 \\
5.5\end{array}$ & $\begin{array}{r}.5 \\
1.3 \\
1.0 \\
.4 \\
.8\end{array}$ & $\begin{array}{r}.11 \\
.67 \\
.32 \\
2.4 \\
.35\end{array}$ \\
\hline $\begin{array}{l}11 \\
12 \\
13 \\
14 \\
15\end{array}$ & $\begin{array}{l}385633105295200 \\
385730105284000 \\
385737105273600 \\
385804105202200 \\
385813105301500\end{array}$ & $\begin{array}{l}75-08-13 \\
75-08-13 \\
75-08-13 \\
75-11-04 \\
75-08-13\end{array}$ & $\begin{array}{r}120 \\
71 \\
128 \\
136 \\
79\end{array}$ & $\begin{array}{l}14 \\
14 \\
18 \\
22 \\
27\end{array}$ & $\begin{array}{l}2.2 \\
4.1 \\
1.9 \\
7.8 \\
12\end{array}$ & $\begin{array}{l}.7 \\
.2 \\
.4 \\
.8 \\
.3\end{array}$ & $\begin{array}{r}2.08 \\
.12 \\
17^{.01} \\
\end{array}$ \\
\hline $\begin{array}{l}16 \\
17 \\
18 \\
19 \\
20\end{array}$ & $\begin{array}{l}385815105200500 \\
385834105205600 \\
385845105211000 \\
385848105212700 \\
385850105221200\end{array}$ & $\begin{array}{l}75-11-04 \\
75-11=04 \\
75-11=04 \\
75-11-04 \\
75-08-13\end{array}$ & $\begin{array}{r}135 \\
5 \\
126 \\
152 \\
173\end{array}$ & $\begin{array}{r}11 \\
390 \\
11 \\
65 \\
25\end{array}$ & $\begin{array}{l}5.8 \\
4.9 \\
5.2 \\
29 \\
12\end{array}$ & $\frac{\frac{2.5}{1.8}}{\frac{3.6}{2.5}}$ & $\begin{array}{r}.25 \\
.02 \\
.01 \\
6.2 \\
.01\end{array}$ \\
\hline $\begin{array}{l}21 \\
22 \\
23 \\
24 \\
25\end{array}$ & $\begin{array}{l}385902105214000 \\
385914105215600 \\
390038105282000 \\
390117105223700 \\
390117105302500\end{array}$ & $\begin{array}{l}75-11-06 \\
75-11-04 \\
75-11=05 \\
75-11-05 \\
75-08=13\end{array}$ & $\begin{array}{r}76 \\
218 \\
395 \\
216 \\
84\end{array}$ & $\begin{array}{l}27 \\
84 \\
49 \\
25 \\
14\end{array}$ & $\begin{array}{l}4.9 \\
59 \\
16 \\
11 \\
1.6\end{array}$ & $\begin{array}{r}\frac{3.8}{1.3} \\
1.2 \\
.9 \\
.4\end{array}$ & $\begin{array}{r}1.5 \\
.01 \\
.15 \\
1.8 \\
.08\end{array}$ \\
\hline $\begin{array}{l}26 \\
27 \\
28 \\
29 \\
30\end{array}$ & $\begin{array}{l}390121105294700 \\
390140105204700 \\
390142105205700 \\
390143105210300 \\
390205105203400\end{array}$ & $\begin{array}{l}75-08-14 \\
75-08-15 \\
75-08-15 \\
75-08-15 \\
75-08-15\end{array}$ & $\begin{array}{r}120 \\
89 \\
197 \\
60 \\
53\end{array}$ & $\begin{array}{l}12 \\
27 \\
78 \\
29 \\
12\end{array}$ & $\begin{array}{l}4.9 \\
91 \\
83 \\
5.6 \\
1.7\end{array}$ & $\frac{5.7}{\frac{5.3}{1.7}} \frac{4.1}{3.1}$ & $\begin{array}{l}.07 \\
.24 \\
1.1 \\
.26 \\
.05\end{array}$ \\
\hline $\begin{array}{l}31 \\
32 \\
33 \\
34 \\
35\end{array}$ & $\begin{array}{l}390417105271100 \\
390514105252800 \\
390552105254500 \\
390602105255500 \\
390638105260700\end{array}$ & $\begin{array}{l}75-08-14 \\
75-11-05 \\
75-08-14 \\
75-08-14 \\
75-08-14\end{array}$ & $\begin{array}{r}142 \\
64 \\
200 \\
63 \\
110\end{array}$ & $\begin{array}{l}22 \\
32 \\
20 \\
25 \\
46\end{array}$ & $\begin{array}{l}11 \\
11 \\
23 \\
5.1 \\
7.8\end{array}$ & $\frac{\frac{.6}{4.5}}{\frac{3.4}{4.6}}$ & $\begin{array}{l}.44 \\
.0 \\
.02 \\
.46 \\
.00\end{array}$ \\
\hline 36 & 390719105282900 & $75-11-06$ & 154 & 31 & 11 & .6 & 1.1 \\
\hline
\end{tabular}


Table 1.--Chemical and bacterial analyses of water from weIls and a spring--Continued

\begin{tabular}{|c|c|c|c|c|c|c|c|}
\hline $\begin{array}{l}\text { SITE } \\
\text { NUM- } \\
\text { BER }\end{array}$ & STATION & $\begin{array}{l}\text { DATE } \\
\text { OF } \\
\text { SAMPLE } \\
(Y-M-D)\end{array}$ & $\begin{array}{l}\text { OIS- } \\
\text { SOLVEO } \\
\text { ORTHO- } \\
\text { PHOS- } \\
\text { PHORUS } \\
\text { (P) } \\
\text { (MG/L) }\end{array}$ & $\begin{array}{c}\text { OIS- } \\
\text { SOLVED } \\
\text { SOLIDS } \\
\text { (SUM OF } \\
\text { CONSTI- } \\
\text { TUENTS) } \\
\text { (MG/L) } \\
{[500]}\end{array}$ & $\begin{array}{l}\text { HARD- } \\
\text { NESS } \\
(C A, M G) \\
(M G / L)\end{array}$ & $\begin{array}{l}\text { NON- } \\
\text { CAR- } \\
\text { BONATE } \\
\text { HARD- } \\
\text { NESS } \\
\text { (MG/L) }\end{array}$ & $\begin{array}{l}\text { SPE- } \\
\text { CIFIC } \\
\text { CON- } \\
\text { DUCT- } \\
\text { ANCE } \\
\text { (MICRO- } \\
\text { MHOS) }\end{array}$ \\
\hline $\begin{array}{l}1 \\
2 \\
3 \\
4 \\
5\end{array}$ & $\begin{array}{l}384857105230800 \\
385046105215000 \\
385050105213800 \\
385100105205200 \\
385426105235100\end{array}$ & $\begin{array}{l}75-08-12 \\
75-08-12 \\
75-08-12 \\
75-08-12 \\
75-11-04\end{array}$ & $\begin{array}{l}.09 \\
.08 \\
.02 \\
.00 \\
.04\end{array}$ & $\begin{array}{l}239 \\
236 \\
144 \\
184 \\
226\end{array}$ & $\begin{array}{r}170 \\
170 \\
7 \\
120 \\
170\end{array}$ & $\begin{array}{r}11 \\
17 \\
0 \\
0 \\
0\end{array}$ & $\begin{array}{l}440 \\
395 \\
250 \\
345 \\
395\end{array}$ \\
\hline $\begin{array}{r}6 \\
7 \\
8 \\
9 \\
10\end{array}$ & $\begin{array}{l}385456105235300 \\
385512105222200 \\
385605105293500 \\
385620105304700 \\
385630105290500\end{array}$ & $\begin{array}{l}75-11-04 \\
75-11-04 \\
75-08-14 \\
75-11-05 \\
75-08-14\end{array}$ & $\begin{array}{l}.06 \\
.01 \\
.01 \\
.01 \\
.01\end{array}$ & $\begin{array}{l}180 \\
218 \\
384 \\
277 \\
235\end{array}$ & $\begin{array}{l}120 \\
170 \\
280 \\
200 \\
170\end{array}$ & $\begin{array}{r}11 \\
0 \\
36 \\
64 \\
14\end{array}$ & $\begin{array}{l}295 \\
385 \\
660 \\
460 \\
407\end{array}$ \\
\hline $\begin{array}{l}11 \\
12 \\
13 \\
14 \\
15\end{array}$ & $\begin{array}{l}385633105295200 \\
385730105284000 \\
385737105273600 \\
385804105202200 \\
385813105301500\end{array}$ & $\begin{array}{l}75-08-13 \\
75-08-13 \\
75-08-13 \\
75-11-04 \\
75-08-13\end{array}$ & $\begin{array}{l}.00 \\
.00 \\
.01 \\
.02 \\
.03\end{array}$ & $\begin{array}{l}164 \\
134 \\
177 \\
214 \\
257\end{array}$ & $\begin{array}{l}110 \\
74 \\
130 \\
160 \\
150\end{array}$ & $\begin{array}{r}0 \\
3 \\
5 \\
27 \\
67\end{array}$ & $\begin{array}{l}280 \\
205 \\
300 \\
345 \\
405\end{array}$ \\
\hline $\begin{array}{l}16 \\
17 \\
18 \\
19 \\
20\end{array}$ & $\begin{array}{l}385815105200500 \\
385834105205600 \\
385845105211000 \\
385848105212700 \\
385850105221200\end{array}$ & $\begin{array}{l}75-11-04 \\
75-11-04 \\
75-11-04 \\
75-11-04 \\
75-08-13\end{array}$ & $\begin{array}{l}.01 \\
.05 \\
.04 \\
.16 \\
.09\end{array}$ & $\begin{array}{l}199 \\
636 \\
203 \\
386 \\
253\end{array}$ & $\begin{array}{l}130 \\
340 \\
100 \\
250 \\
180\end{array}$ & $\begin{array}{r}0 \\
340 \\
0 \\
93 \\
8\end{array}$ & $\begin{array}{l}318 \\
860 \\
295 \\
590 \\
450\end{array}$ \\
\hline $\begin{array}{l}21 \\
22 \\
23 \\
24 \\
25\end{array}$ & $\begin{array}{l}385902105214000 \\
385914105215600 \\
390038105282000 \\
3901117105223700 \\
390117105302500\end{array}$ & $\begin{array}{l}75-11-06 \\
75-11-04 \\
75-11-05 \\
75-11-05 \\
75-08-13\end{array}$ & $\begin{array}{l}.05 \\
.02 \\
.03 \\
.06 \\
.00\end{array}$ & $\begin{array}{l}164 \\
462 \\
509 \\
307 \\
132\end{array}$ & $\begin{array}{r}110 \\
300 \\
350 \\
230 \\
80\end{array}$ & $\begin{array}{r}30 \\
77 \\
0 \\
13 \\
0\end{array}$ & $\begin{array}{l}265 \\
780 \\
840 \\
530 \\
210\end{array}$ \\
\hline $\begin{array}{l}26 \\
27 \\
28 \\
29 \\
30\end{array}$ & $\begin{array}{l}390121105294700 \\
390140105204700 \\
390142105205700 \\
390143105210300 \\
390205105203400\end{array}$ & $\begin{array}{l}75-08-14 \\
75-08-15 \\
75-08-15 \\
75-08-15 \\
75-08-15\end{array}$ & $\begin{array}{l}.00 \\
.00 \\
.01 \\
.01 \\
.02\end{array}$ & $\begin{array}{l}163 \\
318 \\
455 \\
139 \\
101\end{array}$ & $\begin{array}{r}100 \\
72 \\
250 \\
91 \\
59\end{array}$ & $\begin{array}{r}0 \\
0 \\
50 \\
31 \\
6\end{array}$ & $\begin{array}{l}292 \\
590 \\
815 \\
235 \\
165\end{array}$ \\
\hline $\begin{array}{l}31 \\
32 \\
33 \\
34 \\
35\end{array}$ & $\begin{array}{l}390417105271100 \\
390514105252800 \\
390552105254500 \\
390602105255500 \\
390638105260700\end{array}$ & $\begin{array}{l}75-08-14 \\
75-11-05 \\
75-08-14 \\
75-08-14 \\
75-08-14\end{array}$ & $\begin{array}{l}.02 \\
.01 \\
.01 \\
.01 \\
.01\end{array}$ & $\begin{array}{l}213 \\
188 \\
316 \\
151 \\
232\end{array}$ & $\begin{array}{r}140 \\
120 \\
190 \\
90 \\
140\end{array}$ & $\begin{array}{r}0 \\
56 \\
0 \\
27 \\
27\end{array}$ & $\begin{array}{l}375 \\
330 \\
570 \\
234 \\
420\end{array}$ \\
\hline 36 & 390719105282900 & $75-11-06$ & .02 & 241 & 190 & 33 & 430 \\
\hline
\end{tabular}


Table 1.--Chemical and bacterial analyses of water from wells and a spring--Cont inued

\begin{tabular}{|c|c|c|c|c|c|c|c|}
\hline $\begin{array}{l}\text { SITE } \\
\text { NUM- } \\
\text { BER }\end{array}$ & STATION & $\begin{array}{l}\text { DATE } \\
\text { OF } \\
\text { SAMPLE } \\
(Y-M-D)\end{array}$ & $\begin{array}{c}\text { PH } \\
\text { (UNITS) }\end{array}$ & $\begin{array}{l}\text { TEMPER- } \\
\text { ATURE } \\
\text { (DEG C) }\end{array}$ & $\begin{array}{c}\text { FECAL } \\
\text { COLI- } \\
\text { FORM } \\
\text { (COL. } \\
\text { PER } \\
100 \mathrm{ML} \text { ) } \\
{[0]}\end{array}$ & $\begin{array}{c}\text { STREP- } \\
\text { TOCOCCI } \\
\text { COL- } \\
\text { (ONIES } \\
\text { PER } \\
100 \mathrm{ML} \text { ) }\end{array}$ & $\begin{array}{l}\text { DIS- } \\
\text { SOLVED } \\
\text { RERYL- } \\
\text { LIUM } \\
\text { (BE) } \\
(U G / L)\end{array}$ \\
\hline $\begin{array}{l}1 \\
2 \\
3 \\
4 \\
5\end{array}$ & $\begin{array}{l}384857105230800 \\
385046105215000 \\
385050105213800 \\
385100105205200 \\
385426105235100\end{array}$ & $\begin{array}{l}75-08-12 \\
75-08-12 \\
75-08-12 \\
75-08-12 \\
75-11-04\end{array}$ & $\begin{array}{l}7.5 \\
7.4 \\
9.1 \\
7.4 \\
6.9\end{array}$ & $\begin{array}{r}10.0 \\
7.0 \\
13.0 \\
14.0 \\
8.0\end{array}$ & $\begin{array}{l}0 \\
0 \\
0 \\
0 \\
0\end{array}$ & $\begin{array}{l}0 \\
1 \\
0 \\
0 \\
0\end{array}$ & $\begin{array}{l}\because- \\
\therefore \\
\therefore\end{array}$ \\
\hline $\begin{array}{r}6 \\
7 \\
8 \\
9 \\
10\end{array}$ & $\begin{array}{l}385456105235300 \\
385512105222200 \\
385605105293500 \\
385620105304700 \\
385630105290500\end{array}$ & $\begin{array}{l}75-11-04 \\
75-11-04 \\
75-08-14 \\
75-11-05 \\
75-08-14\end{array}$ & $\begin{array}{r}6.4 \\
7.4 \\
-.0 \\
7.0 \\
-.-\end{array}$ & $\begin{array}{r}11.0 \\
9.0 \\
10.0 \\
7.5 \\
10.0\end{array}$ & $\begin{array}{l}0 \\
0 \\
0 \\
0 \\
0\end{array}$ & $\begin{array}{r}0 \\
0 \\
-0 \\
--\end{array}$ & 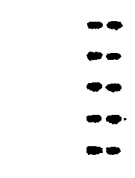 \\
\hline $\begin{array}{l}11 \\
12 \\
13 \\
14 \\
15\end{array}$ & $\begin{array}{l}385633105295200 \\
385730105284000 \\
385737105273600 \\
385804105202200 \\
385813105301500\end{array}$ & $\begin{array}{l}75-08-13 \\
75-08-13 \\
75-08-13 \\
75-11-04 \\
75-08-13\end{array}$ & $\begin{array}{c}-- \\
-0 \\
0.8\end{array}$ & $\begin{array}{r}13.0 \\
11.0 \\
10.0 \\
10.0 \\
9.0\end{array}$ & $\begin{array}{l}0 \\
0 \\
0 \\
0 \\
0\end{array}$ & $\begin{array}{r}0 \\
0 \\
0 \\
2 \\
16 \\
\end{array}$ & $\begin{array}{l}\cdots \\
\cdots \\
\cdots\end{array}$ \\
\hline $\begin{array}{l}16 \\
17 \\
18 \\
19 \\
20\end{array}$ & $\begin{array}{l}385815105200500 \\
385834105205600 \\
385845105211000 \\
385848105212700 \\
385850105221200\end{array}$ & $\begin{array}{l}75-11-04 \\
75-11-04 \\
75-11=04 \\
75-11-04 \\
75-08-13\end{array}$ & $\begin{array}{l}6.8 \\
5.4 \\
7.2 \\
6.3 \\
-.\end{array}$ & $\begin{array}{r}10.0 \\
9.0 \\
9.0 \\
10.0 \\
13.0\end{array}$ & $\begin{array}{l}0 \\
0 \\
0 \\
0 \\
0\end{array}$ & $\begin{array}{l}0 \\
0 \\
0 \\
1 \\
1\end{array}$ & 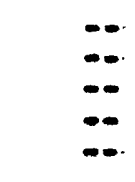 \\
\hline $\begin{array}{l}21 \\
22 \\
23 \\
24 \\
25\end{array}$ & $\begin{array}{l}385902105214000 \\
385914105215600 \\
390038105282000 \\
3901117105223700 \\
390117105302500\end{array}$ & $\begin{array}{l}75-11-06 \\
75-11=04 \\
75-11-05 \\
75-11-05 \\
75-08-13\end{array}$ & $\begin{array}{l}6.9 \\
7.0 \\
6.8 \\
7.3 \\
-.-\end{array}$ & $\begin{array}{l}9.5 \\
7.0 \\
9.5 \\
9.5 \\
9.0\end{array}$ & $\begin{array}{r}0 \\
0 \\
0 \\
0 \\
--\end{array}$ & $\begin{array}{r}0 \\
0 \\
1 \\
0 \\
--\end{array}$ & $=$ \\
\hline $\begin{array}{l}26 \\
27 \\
28 \\
29 \\
30\end{array}$ & $\begin{array}{l}390121105294700 \\
390140105204700 \\
390142105205700 \\
390143105210300 \\
390205105203400\end{array}$ & $\begin{array}{l}75-08-14 \\
75-08-15 \\
75-08-15 \\
75-08-15 \\
75-08-15\end{array}$ & $=-$ & $\begin{array}{r}10.0 \\
9.0 \\
9.0 \\
9.0 \\
10.0\end{array}$ & $\begin{array}{l}0 \\
-- \\
-- \\
--\end{array}$ & $\begin{array}{l}-- \\
-- \\
-- \\
--\end{array}$ & $\because$ \\
\hline $\begin{array}{l}31 \\
32 \\
33 \\
34 \\
35\end{array}$ & $\begin{array}{l}390417105271100 \\
390514105252800 \\
390552105254500 \\
390602105255500 \\
390038105260700\end{array}$ & $\begin{array}{l}75-08-14 \\
75-11-05 \\
75-08-14 \\
75-08-14 \\
75-08-14\end{array}$ & $\begin{array}{r}7.4 \\
6.3 \\
-.- \\
-.\end{array}$ & $\begin{array}{r}7.0 \\
9.5 \\
9.0 \\
10.0 \\
9.0\end{array}$ & $\begin{array}{l}-- \\
0 \\
0 \\
0 \\
0\end{array}$ & $\begin{array}{c}-- \\
0 \\
-- \\
--\end{array}$ & $\begin{array}{r}<10 \\
<10 \\
-\infty\end{array}$ \\
\hline 36 & 390719105282900 & $75-11-06$ & 7.6 & 8.0 & -- & -- & $\infty$ \\
\hline
\end{tabular}

lFigure in brackets indicates the Colorado Department of Health (1976) recommended limits for drinking water. Underlined values exceed these values.

2 spring. 
Table 2.--Chemical and bacterial analyses of water from selected streams $[M G / L=m i l 1$ igrams per liter; $M L=m i l l i l i t e r s ; U G / L=m i c r o g r a m s$ per $1 i t e r]$

\begin{tabular}{|c|c|c|c|c|c|c|c|}
\hline \multirow{2}{*}{$\begin{array}{ll}\begin{array}{l}\text { SI TE } \\
\text { NUM- } \\
\text { BER }\end{array} \\
1 & 0 \\
2 & 3 \\
3 & 3 \\
4 & 3\end{array}$} & STATION NUMBER & & \multicolumn{3}{|c|}{ STATION NAME } & $\begin{array}{l}\text { DATE } \\
\text { OF } \\
\text { SAMPLE } \\
(Y-M-D)\end{array}$ & $\begin{array}{l}\text { INSTAN- } \\
\text { TANEOUS } \\
\text { DIS- } \\
\text { CHARGE } \\
\left(\mathrm{FT}^{3} / \mathrm{S}\right)\end{array}$ \\
\hline & $\begin{array}{l}06696000 \\
385821105213300 \\
390135105205900 \\
390426105240500\end{array}$ & \multicolumn{4}{|c|}{$\begin{array}{l}\text { SOUTH PLATTE RIVER NR LAKE GEORGE } \\
\text { TWIN CK AT MOUTH, NR LAKE GEORGE } \\
\text { SOUTH PLATTE RIVER BLW LAKE GEORGE } \\
\text { TARRYALL CK ABV MOUTH }\end{array}$} & $\begin{array}{l}75-08-11 \\
75-08-11 \\
75-08-11 \\
75-08-11\end{array}$ & $\begin{array}{l}{ }^{1} 150 \\
{ }^{1} 150^{2} \\
12\end{array}$ \\
\hline $\begin{array}{l}\text { DIS- } \\
\text { SOLVED } \\
\text { SILICA } \\
(\text { SIO2) } \\
(M G / L)\end{array}$ & $\begin{array}{l}\text { DIS- } \\
\text { SOLVED } \\
\text { IRON } \\
\text { (FE) } \\
(\mathrm{UG} / \mathrm{L})\end{array}$ & $\begin{array}{l}\text { DIS- } \\
\text { SOLVED } \\
\text { MAN- } \\
\text { GANESE } \\
(M N) \\
(U G / L)\end{array}$ & $\begin{array}{l}\text { DIS- } \\
\text { SOLVED } \\
\text { CAL- } \\
\text { CIUM } \\
\text { (CA) } \\
(\mathrm{MG} / \mathrm{L})\end{array}$ & $\begin{array}{l}\text { DIS- } \\
\text { SOLVED } \\
\text { MAGNE- } \\
\text { SIUM } \\
\text { (MG) } \\
(M G / L)\end{array}$ & $\begin{array}{l}\text { DIS- } \\
\text { SOLVED } \\
\text { SODIUM } \\
\text { (NA) } \\
\text { (MG/L) }\end{array}$ & $\begin{array}{l}\text { DIS- } \\
\text { SOLVED } \\
\text { POTAS- } \\
\text { SIUM } \\
\text { (K) } \\
\text { (MG/L) }\end{array}$ & $\begin{array}{l}\text { BICAR- } \\
\text { BONATE } \\
\text { (HCO3) } \\
\text { (MG/L) }\end{array}$ \\
\hline $\begin{array}{l}3.0 \\
26 \\
2.3 \\
13\end{array}$ & $\begin{array}{r}10 \\
0 \\
30 \\
70\end{array}$ & $\begin{array}{r}0 \\
30 \\
20 \\
30\end{array}$ & $\begin{array}{l}53 \\
52 \\
53 \\
39\end{array}$ & $\begin{array}{l}32 \\
10 \\
34 \\
11\end{array}$ & $\begin{array}{l}84 \\
22 \\
85 \\
10\end{array}$ & $\begin{array}{l}3.5 \\
5.4 \\
3.5 \\
1.3\end{array}$ & $\begin{array}{l}193 \\
193 \\
167 \\
178\end{array}$ \\
\hline $\begin{array}{l}\text { CAR- } \\
\text { BONATE } \\
(\mathrm{CO} 3) \\
(\mathrm{MG} / \mathrm{L})\end{array}$ & $\begin{array}{l}\text { ALKA- } \\
\text { LINITY } \\
\text { AS } \\
\text { CACO3 } \\
\text { (MG/L) }\end{array}$ & $\begin{array}{c}\text { DIS- } \\
\text { SOLVED } \\
\text { SULFATE } \\
\text { (SO4) } \\
\text { (MG/L) }\end{array}$ & $\begin{array}{c}\text { DIS- } \\
\text { SOLVED } \\
\text { CHLO- } \\
\text { RIDE } \\
(\mathrm{CL}) \\
(\mathrm{MG} / \mathrm{L})\end{array}$ & $\begin{array}{l}\text { DIS- } \\
\text { SOLVED } \\
\text { FLUD- } \\
\text { RIDE } \\
(\mathrm{F}) \\
(\mathrm{MG} / \mathrm{L})\end{array}$ & $\begin{array}{c}\text { DIS- } \\
\text { SOLVED } \\
\text { NITRITE } \\
\text { PLUS } \\
\text { NITRATE } \\
\text { (N) } \\
(\mathrm{MG} / \mathrm{L})\end{array}$ & $\begin{array}{l}\text { DIS- } \\
\text { SOLVED } \\
\text { ORTHO- } \\
\text { PHOS- } \\
\text { PHORUS } \\
\text { (P) } \\
\text { (MG/L) }\end{array}$ & $\begin{array}{l}\text { DIS- } \\
\text { SOLVED } \\
\text { SOLIDS } \\
\text { (SUM OF } \\
\text { CONSTI- } \\
\text { TUENTS) } \\
\text { (MG/L) }\end{array}$ \\
\hline $\begin{array}{r}0 \\
0 \\
11 \\
0\end{array}$ & $\begin{array}{l}158 \\
158 \\
155 \\
146\end{array}$ & $\begin{array}{r}120 \\
34 \\
120 \\
13\end{array}$ & $\begin{array}{r}120 \\
19 \\
120 \\
0\end{array}$ & $\begin{array}{r}0.3 \\
3.0 \\
.3 \\
.6\end{array}$ & $\begin{array}{l}0.0 \\
0.0 \\
0.0 \\
0.0\end{array}$ & $\begin{array}{l}0.00 \\
0.04 \\
0.00 \\
0.00\end{array}$ & $\begin{array}{l}511 \\
267 \\
511 \\
176\end{array}$ \\
\hline $\begin{array}{c}\text { HARD- } \\
\text { NESS } \\
(C A, \text { iMG }) \\
(M G / L)\end{array}$ & $\begin{array}{l}\text { NONCAR- } \\
\text { BONATE } \\
\text { HARD- } \\
\text { NESS } \\
\text { (MG/L) }\end{array}$ & $\begin{array}{r}\text { SPECI } \\
\text { CONDU } \\
\text { ANC } \\
\text { (MIC } \\
\text { MHO }\end{array}$ & & & $\begin{array}{l}\text { EMPER- } \\
\text { ATURE } \\
\text { DEG C) }\end{array}$ & $\begin{array}{c}\text { FECAL } \\
\text { COLIFORM } \\
\text { (COLONIES } \\
\text { PER } \\
100 \mathrm{ML} \text { ) }\end{array}$ & $\begin{array}{c}\text { STREP- } \\
\text { TOCOCCI } \\
\text { (COLONIES } \\
\text { PER } \\
100 \mathrm{ML} \text { ) }\end{array}$ \\
\hline $\begin{array}{l}260 \\
170 \\
270 \\
140\end{array}$ & $\begin{array}{r}110 \\
13 \\
120 \\
0\end{array}$ & $\begin{array}{l}95 \\
45 \\
93 \\
32\end{array}$ & & 5 & $\begin{array}{l}18.0 \\
21.0 \\
21.0 \\
17.0\end{array}$ & $\begin{array}{r}0 \\
5 \\
2 \\
10\end{array}$ & $\begin{array}{r}15 \\
100 \\
16 \\
30\end{array}$ \\
\hline
\end{tabular}

${ }^{1}$ Discharge estimated. 
Water types found in the Lake George study area are shown on figure 3. The circular diagrams are subdivided on the basis of percentage of milliequivalents per liter of major ions present. The diagrams were chosen to show differences in water types for the aquifers and conditions present in the study area.

The crystalline-rock aquifer contains calcium bicarbonate water. Calcium bicarbonate water with concentrations of dissolved solids less than $500 \mathrm{mg} / \mathrm{L}$ is ideal for most uses. However, in some areas, minor ions found in the ground water may affect the suitability for domestic use. In particular, dissolved iron and (or) dissolved fluoride exceeded the recommended limits for drinking water (Colorado Department of Health, 1976) in samples from 18 wells shown in table 1.

Large concentrations, 10,000 and 18,000 $\mu \mathrm{g} / \mathrm{L}$ (micrograms per $1 \mathrm{iter}$ ), of dissolved iron were found in water from wells 35 and 33 (table 1 and fig. 4) tapping the crystalline-rock aquifer in the north-central part of the study area. These dissolved iron concentrations, which exceeded the recommended limit of $300 \mu \mathrm{g} / \mathrm{L}$ for drinking water (Colorado Department of Health, 1976), are thought to be related to a mineralized zone found along fractured areas in the aquifer. These concentrations appear quite localized because water from nearby wells contains no dissolved iron. These concentrations of dissolved iron do not constitute a health hazard but do cause staining of plumbing fixtures, laundry, and cooking utensils, and impart objectionable taste and color to food and drink. Water containing dissolved iron in concentrations exceeding $300 \mu \mathrm{g} / \mathrm{L}$ is unsuitable for domestic use without chemical treatment.

Concentrations of dissolved fluoride which exceeded the recommended limit of $1.3 \mathrm{mg} / \mathrm{L}$ for drinking water (Colorado Department of Health, 1976) are present primarily in water from the crystalline-rock aquifer in the northeastern part of the study area (fig. 5). Water from wells tapping the crystalline-rock aquifer in the northeastern part of the study area have concentrations of dissolved fluoride that ranged from 0.9 to $5.6 \mathrm{mg} / \mathrm{L}$. These concentrations are caused by solution of apatite and biotite, minerals containing fluoride. When fluoride is naturally present in a domestic water supply, it is recommended by the Colorado Department of Health (1976) that the concentrations occur between specific limits. These limits are a function of air temperature and decrease with increasing temperatures on the assumption that more water is consumed by individuals in a hotter environment. For the Lake George area, the recommended lower limit is $0.8 \mathrm{mg} / \mathrm{L}$ and the recommended upper limit is $1.3 \mathrm{mg} / \mathrm{L}$. Dissolved fluoride in concentrations exceeding $1.3 \mathrm{mg} / \mathrm{L}$ can cause mottling and disfiguration of children's teeth if consumed over a period of years. However, water with these concentrations of fluoride can be suitable for domestic use by adults or by children if the total amount of water ingested is controlled. 


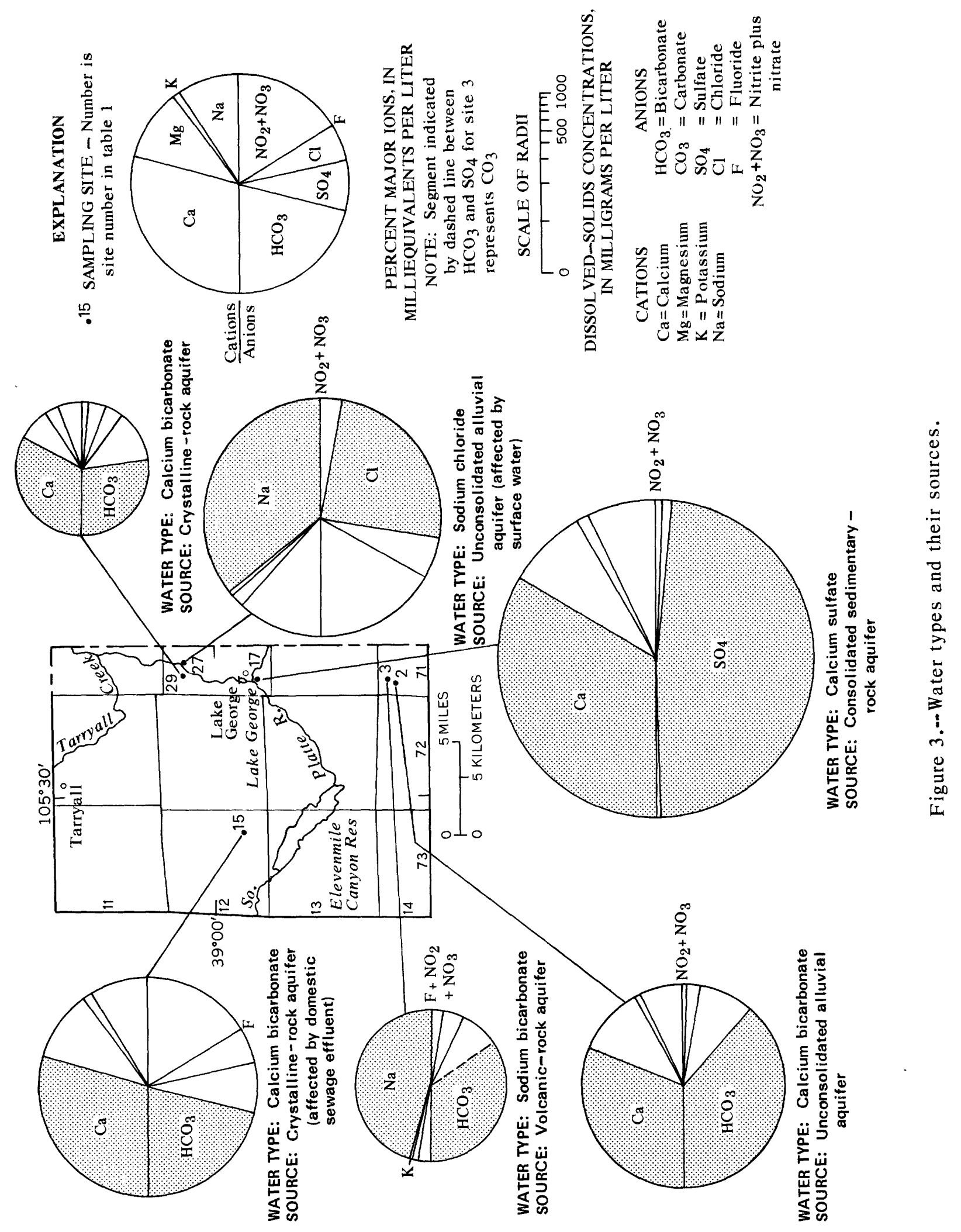



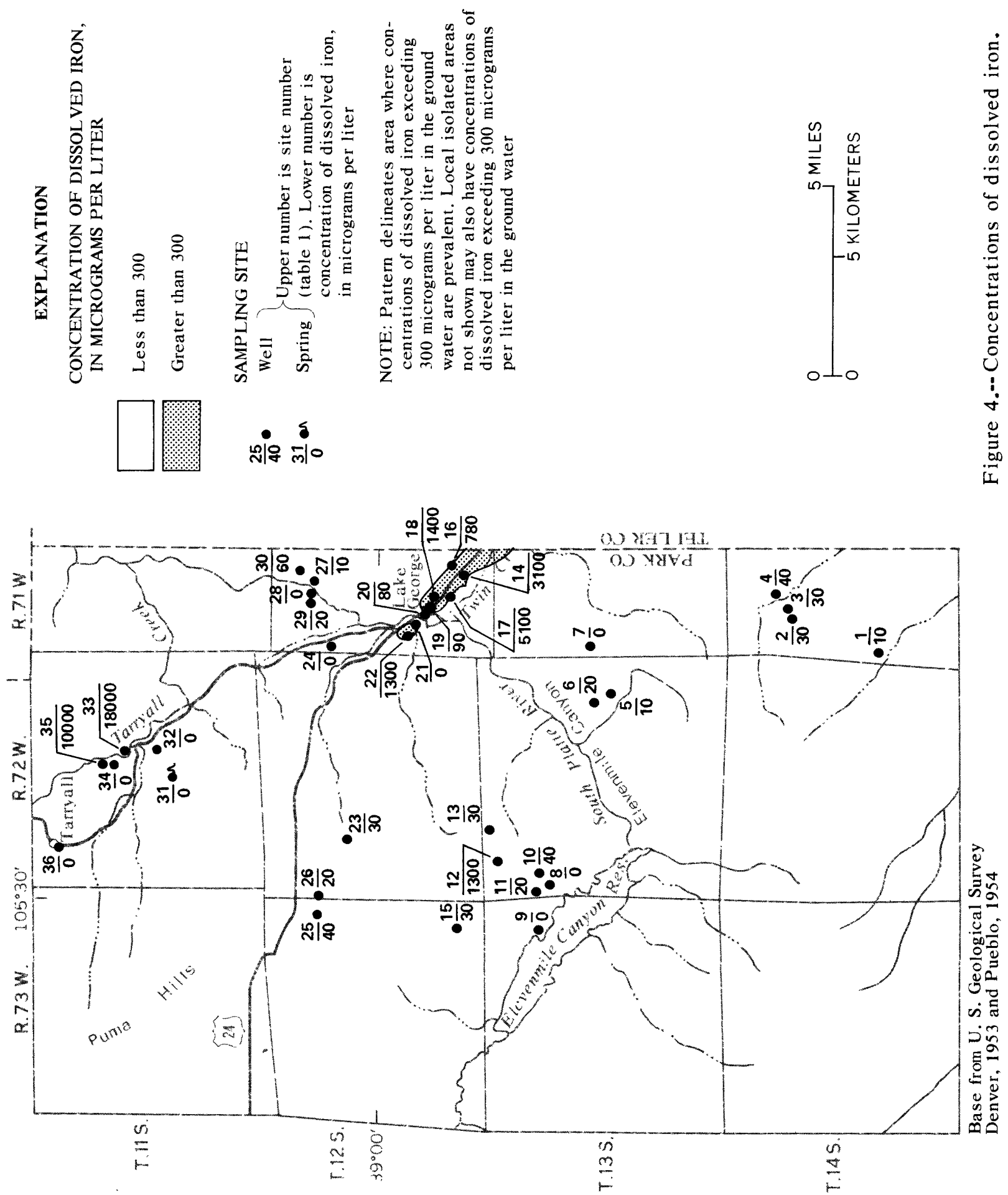

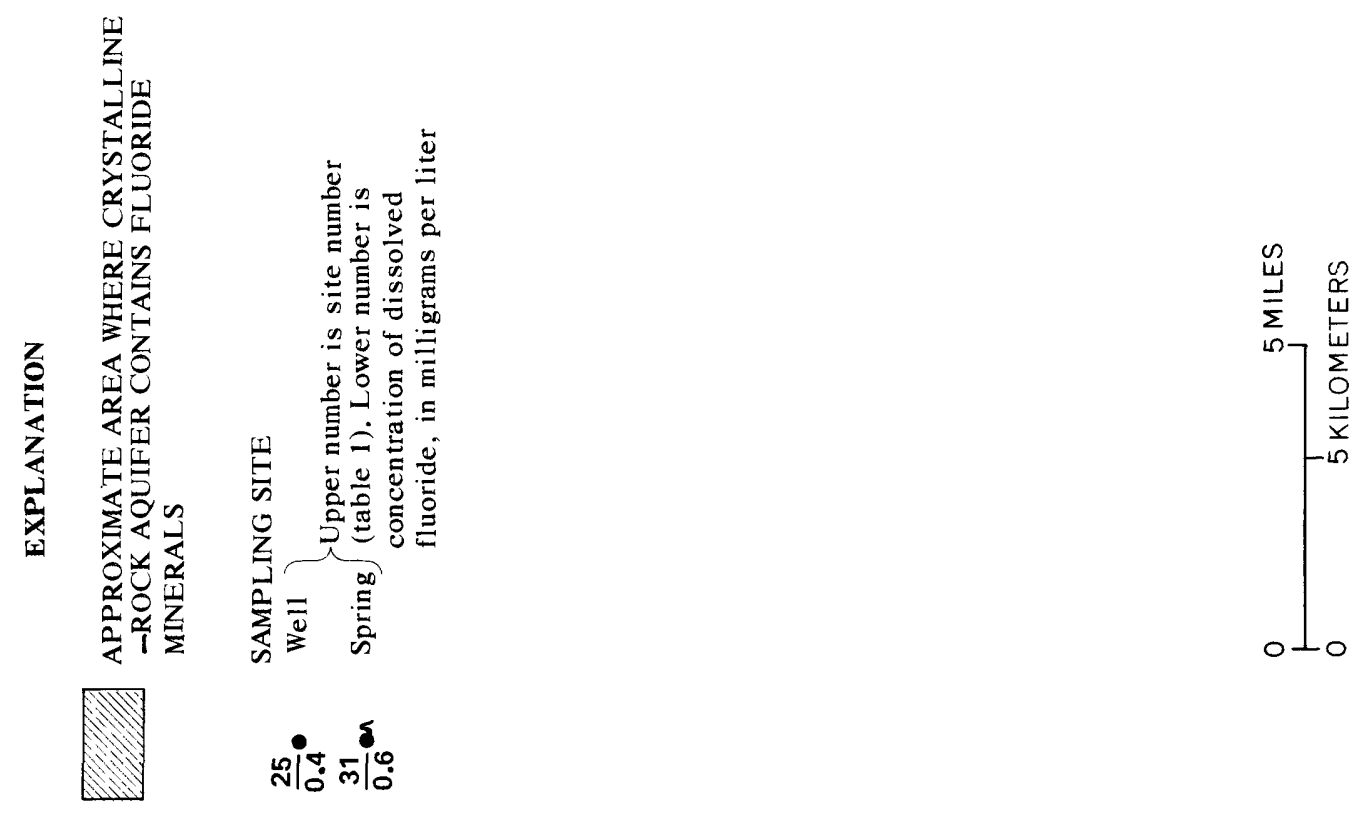

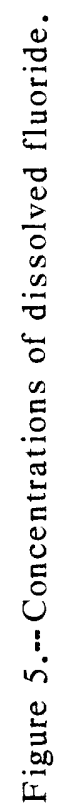

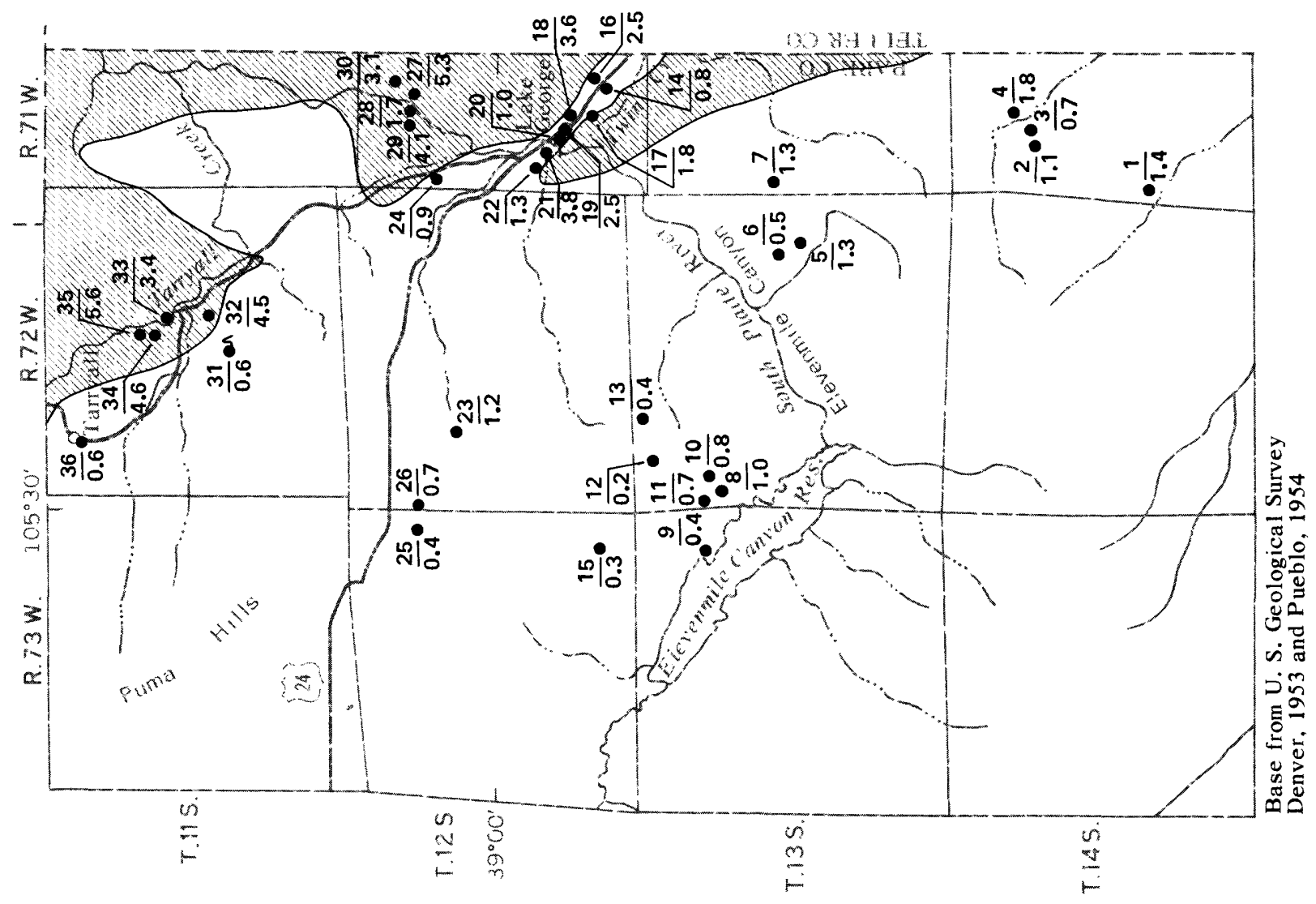


Due to lack of development in the southwestern part of the study area, few wells tap the volcanic-rock aquifer. Only two wells (wells 1 and 3 , fig. 2 and table 1) that yield water from the aquifer were sampled during the study. Water from these wells may represent local conditions only and may not be representative of the general quality of water from the volcanic-rock aquifer.

Dissolved-solids concentrations in water from these two wells were $144 \mathrm{mg} / \mathrm{L}$ from well 3 and $239 \mathrm{mg} / \mathrm{L}$ from well 1 . In contrast, water from similar volcanic rocks located about 20 miles west of the study area contained dissolved-solids concentrations ranging from 800 to $3,300 \mathrm{mg} / \mathrm{L}$ (Klein and others, 1978). Water with dissolved-solids concentrations greater than $500 \mathrm{mg} / \mathrm{L}$ is undesirable for domestic use. It is not known whether water in the volcanic-rock aquifer in other parts of the study area contains dissolvedsolids concentrations greater than that in water from wells 1 and 3 .

Water from the two wells is markedly different in composition. Well 1 yields a calcium bicarbonate water similar to water found in the crystalline rocks. Well 3 yields a sodium bicarbonate water (fig. 3 ). Both of these waters are different from the calcium sulfate water that occurs in the volcanic rocks west of the study area.

More extensive water sampling is needed before the chemical character of water from the volcanic-rock aquifer can be adequately evaluated. Dissolvedsolids concentrations and water types seem to be quite variable; however, it should be noted that both wells sampled yield water suitable for domestic use.

\section{Consolidated Sedimentary-Rock Aquifer}

The consolidated sedimentary-rock aquifer yields water chemically distinguishable from water produced from other aquifers near the town of Lake George. Dissolved-solids concentrations are generally greater in water from the aquifer than in water from other bedrock aquifers present in the study area. The dissolved-solids concentrations ranged from 203 to $636 \mathrm{mg} / \mathrm{L}$ for the four wells sampled. The dissolved-solids concentration of $636 \mathrm{mg} / \mathrm{L}$ from well 17 was the highest concentration of dissolved solids found in water from any well sampled during the study. It was also the only concentration that significantly exceeded the Colorado Department of Health (1976) recommended limit of $500 \mathrm{mg} / \mathrm{L}$ for dissolved solids in drinking water.

Two water types were found to occur in the aquifer. Most of the wells yield a calcium bicarbonate water; however, well 17 yields a calcium sulfate water (fig. 3).

Concentrations of dissolved iron in water from the aquifer ranged from 1,300 to $5,100 \mu \mathrm{g} / \mathrm{L}$ (fig. 4) and exceeded the recommended $1 \mathrm{imit}$ of $300 \mu \mathrm{g} / \mathrm{L}$ 
for drinking water. Without chemical treatment, water from the aquifer is generally unacceptable for domestic use due to the concentrations of dissolved iron.

\section{Unconsolidated Alluvial Aquifers}

Due to variation in composition of the alluvial deposits and differing characteristics of the recharge water, the chemical characteristics of water from unconsolidated alluvial aquifers can be expected to vary seasonally and by location. During the late summer and fall sampling period, the concentration of dissolved solids was generally greater in water from alluvial aquifers than in water from bedrock aquifers. Dissolved-solids concentrations ranged from 213 to $455 \mathrm{mg} / \mathrm{L}$. These concentrations are thought to be caused by several seasonal factors, such as evapotranspiration of water from shallow water-table aquifers which tends to concentrate the dissolved solids in the water remaining in the aquifers, and recharge by surface water containing greater concentrations of dissolved solids.

The type of water found in alluvial aquifers is also dependent upon the particular aquifer from which it is produced. The thin discontinuous alluvial aquifers that occupy most valleys in the study area contain calcium carbonate water similar to that water contained in the local bedrock aquifers. The water produced from wells located in the alluvium along the South Platte River is chemically different. The South Platte River contains an unusually large concentration of sodium chloride (table 2) derived from salt springs located upstream. Water in the alluvium reflects these sodium chloride concentrations and is a sodium chloride water. Examples of the calcium bicarbonate and sodium chloride waters found in alluvial aquifers are shown on figure 3 .

If a water-quality problem exists in the local bedrock aquifer or in the recharge water, a water-quality problem is likely to exist in the alluvial aquifer as well. Concentrations of dissolved fluoride exceeded the recommended $1 \mathrm{imit}$ of $1.3 \mathrm{mg} / \mathrm{L}$ for drinking water (Colorado Department of Health, 1976) in water from wells located in alluvial aquifers comprised of weathered materials containing apatite and biotite. However, in general, water from the alluvial aquifers is suitable for domestic use.

\section{Effects of Domestic Waste Disposal on Ground-Water Quality}

The usual pattern of residential development in rural areas is for each home owner to drill a well for a potable water supply and to install a septic tank or cesspool system to dispose of household waste. Due to economic or space limitations, both the well and waste-disposal systems are generally located near the house, consequently within a short distance of one another. Such is the case in the Lake George study area. Thirty-three of the 36 ground-water samples obtained during the study were from wells located near domestic waste-disposal systems. 
On-site treatment of domestic waste is usually accomplished by the installation of a septic-tank system. There are two components of a septictank system--first, the septic tank (or cesspool), itself, which removes solid matter and provides some anaerobic treatment and, second, a subsurface system, such as a trench bed or leach field, which receives liquid effluent from the septic tank and allows it to seep slowly through the soil where the sewage is treated aerobically by soil micro-organisms. The majority of treatment occurs in the subsoil during the second phase of treatment.

Soil serves as the medium which absorbs and filters the effluent, and the efficiency of a septic-tank system is largely dependent upon the nature and thickness of the soil. If the soil is too thin or too permeable, the effluent will pass rapidly through and not undergo sufficient purification. In instances where a thin soil cover exists over fractured rock, the problem is multiplied, because poorly treated effluent moves rapidly into the fractures and into the ground-water system.

Previous studies of fractured-rock aquifer systems show that contamination in the form of nitrate, bacteria, and viruses can move freely for hundreds of feet (Franks, 1972; Allen and Morrison, 1973). In areas along the Front Range in Colorado, studies by Hofstra and Hall (1975) and Klein, Goddard, and Livingston (1978) indicate that degradation of ground-water supplies in crystalline-rock aquifers is a problem and possible health hazard. Similar geohydrologic conditions exist in the area surrounding Lake George with potential for contamination and resultant health problems.

During this study, it was necessary to distinguish between concentrations of chemical constituents in undegraded water and the concentrations present in degraded water. To establish concentrations in undegraded water, samples of water from sparsely settled areas were analyzed and compared. Concentrations present in undegraded water from similar aquifers determined in other studies were compared with data collected during this study. It was therefore possible to determine what samples were degraded and to what degree.

Various chemical factors were examined to determine the presence and degree of degradation in water in the crystalline-rock aquifer. Chemical ions generally present in domestic effluent which are not removed by natural filtration are dissolved potassium, dissolved chloride, dissolved phosphorus, and dissolved nitrate. Of these, dissolved nitrate, in the form of dissolved nitrite plus nitrate as nitrogen, is the best indication of degradation. In the study area, there are few natural sources of nitrate in the bedrock aquifers and concentrations of nitrate in undegraded ground water are relatively small. Sewage effluent and seepage from domestic-animal pens contain relatively large nitrate concentrations, and relatively large concentrations of nitrate in grourid water are indicative of degradation from these sources.

Twenty-four of the 36 ground-water samples had concentrations of less than $0.5 \mathrm{mg} / \mathrm{L}$ dissolved nitrite plus nitrate as nitrogen and 17 of those 
samples had concentrations of less than $0.25 \mathrm{mg} / \mathrm{L}$. It was determined from these data that undegraded ground water in the study area contains less than $0.25 \mathrm{mg} / \mathrm{L}$ dissolved nitrite plus nitrate as nitrogen. This determination agrees closely with data from a study by Hofstra and Hall (1975). In their study of crystalline rocks in western Jefferson County, they used a value of $0.20 \mathrm{mg} / \mathrm{L}$ as the demarcation between undegraded and degraded ground water.

Eighteen of the wells and the one spring sampled had concentrations of dissolved nitrite plus nitrate as nitrogen equal to or greater than $0.25 \mathrm{mg} / \mathrm{L}$. These wells can be considered to be in areas of degraded ground water. However, water from most wells had concentrations of dissolved nitrite plus nitrate as nitrogen only slightly in excess of $0.25 \mathrm{mg} / \mathrm{L}$. The recommended limit of $10 \mathrm{mg} / \mathrm{L}$ dissolved nitrite plus nitrate as nitrogen for drinking water (Colorado Health Department, 1976) was exceeded only in water from well 15, which had a concentration of $17 \mathrm{mg} / \mathrm{L}$. At concentrations greater than $10 \mathrm{mg} / \mathrm{L}$, dissolved nitrite plus nitrate as nitrogen is known to cause methemoglobinemia (blue-baby disease), a serious and occasionally fatal blood disorder in infants who are less than 9 months old (National Academy of Sciences and National Academy of Engineering, 1974). Methemoglobinemia in infants can be avoided if pregnant women and infants drink water from other sources.

When concentrations of dissolved nitrite plus nitrate as nitrogen are mapped (fig. 6), wells considered as yielding degraded ground water are located in most developed areas. Some isolated wells also can yield degraded water. The areas delineated on figure 6 probably have widespread degradation caused by nitrate. Domestic-waste disposal is the most probable source of this ground-water degradation.

Poorly functioning septic systems are responsible for addition of effluent containing relatively large concentrations of nitrate to the groundwater system. Properly engineered leach-field systems, such as special subsurface soil-absorption systems or above-ground mound systems, can reduce the amount of nitrate entering the ground-water system. However, some nitrate is present in effluent discharged from properly functioning domestic-waste disposal units. Sewage-treatment plants can remove more nitrate than the most effective individual waste-disposal system, and recharge of the aquifer with sewage-plant effluent could reduce nitrate problems. In some instances where consumptive use of the ground water would not create legal problems, closed systems using incineration or evaporation could be used to prevent addition of nitrate to the ground-water system.

Human wastes also contain, in addition to numerous chemical constituents, quantities of bacteria, fungi, protozoa, and viruses. If this biological waste does not undergo sufficient filtration in the waste-disposal system, large numbers of these micro-organisms can enter the ground water. As some of these organisms are disease-producing (pathogenic) if ingested, water which contains fecal organisms is considered unsuitable for domestic water supply. 

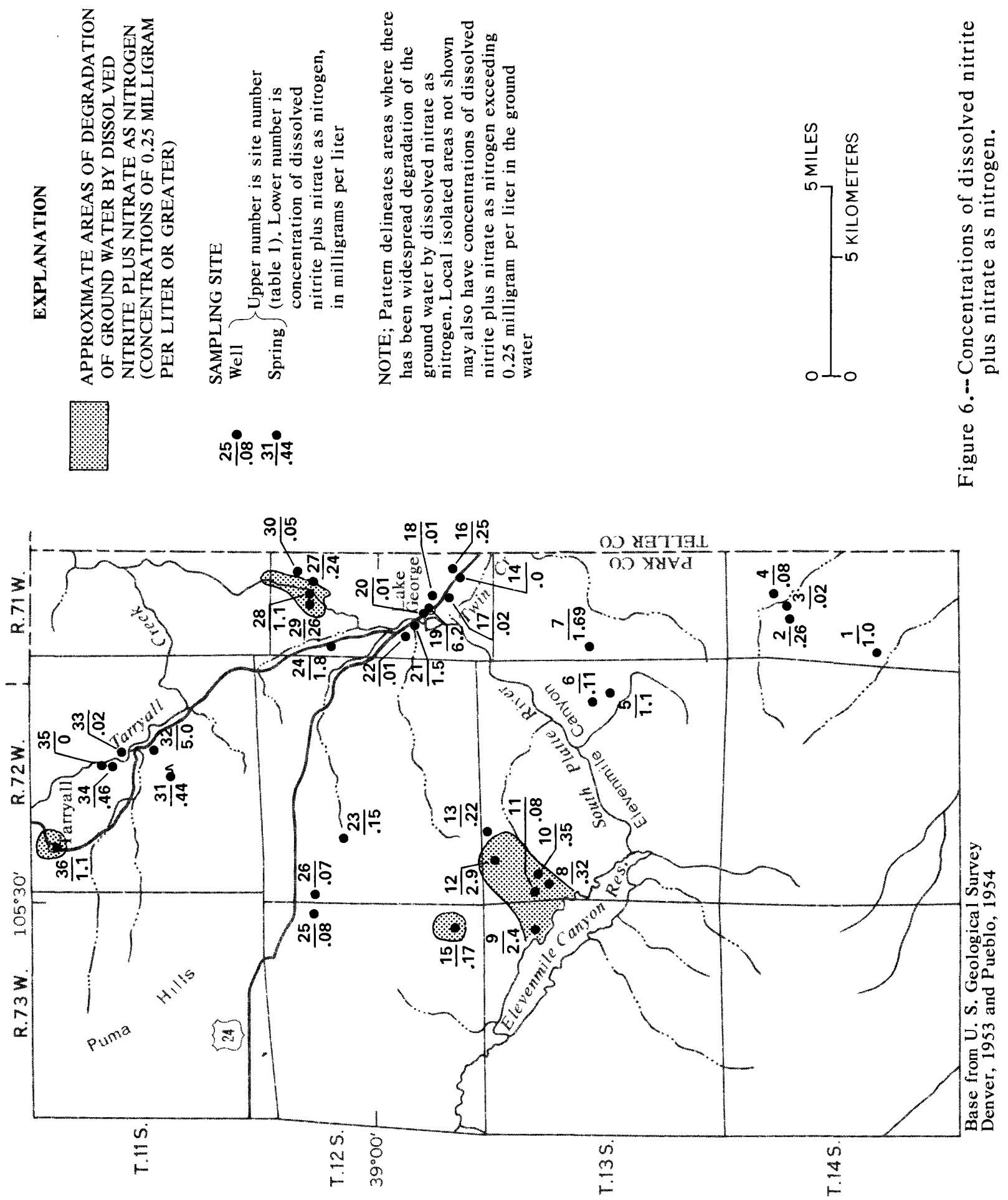
Rather than test for all the individual pathogens which could be present, a single test to determine the presence or absence of an indicator organism is used. The coliform group of bacteria is commonly used as such an indicator. A number of species in the coliform group of bacteria are collectively grouped under the name fecal coliform, which are, by definition, coliform bacteria found in the intestinal tract of warm-blooded animals and are abundant in feces. A second group of bacteria, known as fecal streptococcus, also is present in fecal material and is sometimes used as an indicator. The die-off rates of indicator bacteria outside the intestinal tract are rapid. Therefore, there is a high probability that the presence of fecal-coliform or fecal-streptococcus bacteria in water indicates that pathogenic bacteria and viruses also will be present. Lack of fecal-coliform and fecal-streptococcus bacteria indicates lack of pathogenic organisms.

Membrane-filtration tests for fecal-coliform and fecal-streptococcus bacteria were made at the sites of all the wells and the spring that were sampled. The data are shown in table 1. Fecal-coliform bacteria were not found in any of the samples. However, fecal-streptococcus bacteria were present in water from wells $2,14,15,19,20$, and 23 . The die-off rate is faster for fecal-coliform bacteria than for fecal-streptococcus bacteria. In the case of the six contaminated wells, the traveltime between the sewage source and the well was sufficiently long that all the fecal-coliform bacteria had died and the only remaining indication of contamination was the concentrations of fecal-streptococcus bacteria. Only in water from wells 14 and 15 was the bacterial concentration greater than 1 colony per $100 \mathrm{~mL}$ (milliliters) of water. If a well is found to be bacterially contaminated, a chlorinating system can be added to treat the water before use.

The presence of bacteria in a water sample does not always correlate with chemical contamination indices. In three of the six wells in which bacteria were found, nitrate concentrations did not equal or exceed $0.25 \mathrm{mg} / \mathrm{L}$. However, water from wells 15 and 19 that had the two highest concentrations of dissolved nitrite plus nitrate as nitrogen also contained some bacteria.

A concentration of 16 colonies per $100 \mathrm{~mL}$ of fecal-streptococcus bacteria was found in water from well 15, which also had a concentration of dissolved nitrite plus nitrate as nitrogen of $17 \mathrm{mg} / \mathrm{L}$. These values were the largest found in water from any of the wells sampled during the study.

of the 35 wells and 1 spring that were sampled, only water from well 15 had been degraded by domestic wastes to the extent that the water was unsuitable for domestic use. The percentage of wells containing water unsuitable for domestic use located in similar geologic conditions in northeastern Park and western Jefferson Counties during recent studies was much greater. Development in the Lake George area has not yet reached the proportions it has in these areas. If it does, large-scale degradation of the ground-water reservoir may be expected. Even now, serious degradation could develop in some areas from full-time use of all the currently existing wells and septic tanks. 


\section{SUMMARY}

Residential development in the Lake George area is increasing. With the addition of more wells and on-site sewage-disposal systems, the stress placed on the ground-water system to assimilate domestic wastes will increase. If an adequate supply of potable ground water is to be available in the future, environmental water-quality problems need to be resolved. This report has presented hydrologic data which can be used by individuals or governmental agencies to help reduce water shortages and maintain or improve water quality.

Ground water occurs in crystalline-rock, volcanic-rock, consolidated sedimentary-rock, and unconsolidated alluvial aquifers throughout the study area and is the source of most domestic-water supplies. Few wells are capable of yielding 50 gallons per minute, but well yields are adequate for domestic supply if water use is controlled. Even wells that yield 0.5 to 3 gallons per minute are satisfactory for domestic use provided there is an adequate storage facility.

Mineralogical composition of the aquifers present in the Lake George study area affect the suitability of ground water for domestic use. Concentrations of dissolved iron and (or) dissolved fluoride in water from 18 of the 35 wells and 1 spring that were sampled exceeded the Colorado Department of Health (1976) recommended limits for drinking water. However, either use of a properly designed and maintained treatment system or simple precautionary measures can alleviate any esthetic problems associated with dissolved iron or health problems associated with dissolved fluoride.

Disposal of domestic wastes using septic-tank systems has resulted in both chemical degradation and bacterial contamination of ground-water supplies, although the problems are not serious at the present time (1976). Chemical degradation and bacterial contamination are most prevalent where residential development is concentrated.

Concentrations of dissolved nitrite plus nitrate as nitrogen equal to or greater than $0.25 \mathrm{mg} / \mathrm{L}$ were determined to be indicative of chemical degradation of ground water. Water from 18 of the 35 wells and the 1 spring that were sampled contained concentrations of dissolved nitrite plus nitrate as nitrogen equal to or greater than $0.25 \mathrm{mg} / \mathrm{L}$. However, only one well produced water with a concentration greater than $10 \mathrm{mg} / \mathrm{L}$, the limit for drinking water established by the Colorado Department of Health (1976).

Bacterial contamination, indicated by the presence of fecal-streptococcus bacteria, was found to occur in water from six wells. However, only two wells contained water with bacteria concentrations greater than 1 colony per $100 \mathrm{~mL}$ of water.

Only three wells contained water that was both chemically degraded and bacterially contaminated. Water from one well contained $17 \mathrm{mg} / \mathrm{L}$ dissolved nitrite plus nitrate as nitrogen and a bacteria concentration of 16 colonies 
per $100 \mathrm{~mL}$ of water; both values were the largest found in water from any well sampled during the study.

Because of the geohydrologic characteristics of the aquifers in the study area, chemical degradation and bacterial contamination of ground water may be expected to increase as additional homes are built and domestic wastes are disposed of by septic-tank systems. Some short-term methods of controlling the problem are:

1. Installing a chlorinating system to treat water before use if the water is presently contaminated by bacteria.

2. Increasing the efficiency of existing septic-tank systems that are not functioning properly.

3. Using engineered leach-field systems, such as suisurface soil-absorption systems or above-ground mound systems, that can reduce chemical degradation and bacterial contamination yet retain the economic advantages of individual-treatment systems.

4. Using closed incineration or evaporation systems where consumptive use of ground water would not be a legal problem.

Eventually, as the number of septic-tank systems increases, a point may be reached where the ground-water system will no longer be able to assimilate domestic wastes. If this occurs, some method of collective sewage treatment will be needed.

\section{SELECTED REFERENCES}

Allen, M. J., and Morrison, S. M., 1973, Bacterial movement through fractured bedrock: Ground Water, v. 11 , no. 2, p. 6-10.

American Public Health Association, 1971, Standard methods for the examination of water and wastewater, 13th ed.: Washington, D.C., 874 P.

Brown, Eugene, Skougstad, M. W., and Fishman, M. J., 1970, Methods for collection and analysis of water samples for dissolved minerals and gases: U.S. Geological Survey Techniques of Water-Resources Investigations, book 5, chap. A4, $165 \mathrm{p}$.

Colorado Department of Health, 1971, Laws and regulations applying to potable drinking water supply systems, January 1971: Division of Engineering Sanitation, $8 \mathrm{p}$.

1976, Report of numbers subcommittee to committee on Colorado water quality standards and stream classification, July 1976: $21 \mathrm{p}$.

Fair, G. H., and Heyer, J.C., 1958, Elements of water supply and wastewater disposal: New York, John Wiley, $615 \mathrm{p}$.

Franks, A. L., 1972, Geology for individual sewage disposal systems: California Geology, September 1972 , p. 195-203. 
Geldreich, E. E., 1966, Sanitary significance of fecal coliforms in the environment: Washington, D.C., U.S. Government Printing office, no. $828-355-6,110 \mathrm{p}$.

Goerlitz, D. F., and Brown, Eugene, 1972, Methods for analysis of organic substances in water: U.S. Geological Survey Techniques of Water-Resources Investigations, book 5 , chap. A3, $40 \mathrm{p}$.

Goldstein, S. N., and Moberg, W. J., Jr., 1973, Wastewater treatment systems for rural communities: Washington, D.C., Commission on Rural Water, $340 \mathrm{p}$.

Hofstra, W. E., and Hall, D. C., 1975, Geologic control of supply and quality of water in the mountainous part of Jefferson County, Colorado: Colorado Geological Survey Bulletin 36, $51 \mathrm{p}$. compilers, 1975, Hydrogeologic and water-quality data in western Jefferson County, Colorado: Colorado Water Conservation Board Water Resources Basic-Data Release 36, $51 \mathrm{p}$.

Klein, J. M., Goddard, K. E., and Livingston, R. K., 1978, Appraisal of the water resources of Park and Teller Counties, Colorado: Colorado Water Conservation Board Water-Resources Circular 36 [in press].

Lewis, D. C., and Burgy, R. H., 1964, Hydraulic characteristics of fractured and jointed rock: Ground Water, v. 2, no. 3, p. 4-9.

National Academy of Sciences and National Academy of Engineering, 1974, Water quality criteria, 1972: U.S. Environmental Protection Agency, EPAR3-73-033, $594 \mathrm{p}$.

Romero, J. C., 1972, The movement of bacteria and viruses through porous media, in Pettyjohn, W. A., ed., Water quality in a stressed environment: Minneapolis, Burgess Publishing Co., 309 p.

Slack, K. V., Averett, R. C., Greeson, P. E., and Lipscomb, R. G., 1973, Methods for collection and analysis of aquatic biological and microbiological samples: U.S. Geological Survey Techniques of Water-Resources Investigations, book 5 , chap. A4, $165 \mathrm{p}$.

Snow, D. T., 1968, Hydraulic characteristics of fracture metamorphic rocks of the Front Range and implications to the Rocky Mountain Arsenal well: Golden, Colorado School of Mines Quarterly, v. 63, no. 1, 32 p.

Todd, D. K., 1959, Ground water hydrology: New York, John Wi ley, 336 p.

U.S. Public Health Service, 1962, Drinking water standards: Publication 956, $61 \mathrm{p}$.

Waltz, J. P., 1972, Methods of geologic evaluation of pollution potential at mountain homesites: Ground Water, v. 10, no. 1, p. 42-49.

Wolf, H.W., 1971, The coliform count as a measure of water quality, in Mitchell, Ralph, ed., Water pollution. microbiology: New York, John Wiley, $416 \mathrm{p}$. 